\title{
Response of Metallic Pyramidal Lattice Core Sandwich Panels to High Intensity Impulsive Loading in Air
}

\section{Citation}

Dharmasena, Kumar P., Haydn N. G. Wadley, Keith Williams, Zhenyu Xue, and John W. Hutchinson. 2011. Response of metallic pyramidal lattice core sandwich panels to high intensity impulsive loading in air. International Journal of Impact Engineering 38(5): 275-289.

\section{Published Version}

doi:10.1016/j.ijimpeng.2010.10.002

\section{Permanent link}

http://nrs.harvard.edu/urn-3:HUL.InstRepos:10163030

\section{Terms of Use}

This article was downloaded from Harvard University's DASH repository, and is made available under the terms and conditions applicable to Open Access Policy Articles, as set forth at http:// nrs.harvard.edu/urn-3:HUL.InstRepos:dash.current.terms-of-use\#OAP

\section{Share Your Story}

The Harvard community has made this article openly available.

Please share how this access benefits you. Submit a story.

\section{Accessibility}




\title{
Response of Metallic Pyramidal Lattice Core Sandwich Panels to High Intensity Impulsive Loading in Air
}

\author{
Kumar P. Dharmasena* and Haydn N.G. Wadley \\ Department of Materials Science \& Engineering \\ University of Virginia \\ Keith Williams \\ Force Protection Industries \\ Edgefield, SC \\ Zhenyu Xue and John W. Hutchinson \\ Division of Engineering and Applied Sciences \\ Harvard University
}

\begin{abstract}
Small scale explosive loading of sandwich panels with low relative density pyramidal lattice cores have been used to study the large scale bending and fracture response of a model sandwich panel system in which the core has little stretch resistance. The panels were made from a ductile stainless steel and the practical consequence of reducing the sandwich panel face sheet thickness to induce a recently predicted beneficial fluidstructure interaction (FSI) effect was investigated. The panel responses are compared to those of monolithic solid plates of equivalent areal density. The specific impulse imparted to the panels was varied from 1.5 to $7.6 \mathrm{kPa}$.s by changing the standoff distance between the charge center and the front face of the panels. A decoupled finite element model has been used to computationally investigate the dynamic response of the panels. It predicts panel deformations well and is used to identify the deformation time sequence and the face sheet and core failure mechanisms. The study shows that efforts to use thin face sheets to exploit FSI benefits are constrained by dynamic fracture of the front face and that this failure mode is in part a consequence of the high strength of the inertially stabilized trusses. Even though the pyramidal lattice core offers little in-plane stretch resistance, and the FSI effect is negligible during loading by air, the sandwich panels are found to suffer slightly smaller back face deflections and transmit smaller vertical component forces to the supports compared to equivalent monolithic plates.
\end{abstract}

Keywords: Air Blast, Fluid-structure interaction, Pyramidal core, Sandwich panels (to appear in Int. J. Impact Engineering) 


\section{Introduction}

Sandwich panel structures made from ductile metals with square and triangular honeycomb cores have shown promise for mitigating some of the effects of localized shock loading in air and water $[1,2]$. Recent experiments have shown that the back face deflections of centrally loaded edge clamped sandwich panels can be significantly less than equivalent areal density solid plates subjected to the same loading [3-8]. Theoretical assessments indicate this beneficial effect arises from two phenomena: a reduction in the impulse acquired by the sandwich panel front face as a result of a fluid-structure interaction (FSI) effect [3,4,8-10] and the higher flexural stiffness and strength of the sandwich. It has also been experimentally shown that the forces transmitted to supports when rigid back supported sandwich panels are impulsively loaded in water are significantly less than equivalent solid plates [11-14]. These reductions arise from a combination of beneficial FSI effects (which reduce the transmitted impulse) and a low core crushing stress. Decreasing the core strength then provides a means for reducing the reaction forces transmitted to the protected structure during uniform impulse loading provided the core is sufficiently thick that it does not fully densify during crushing $[11,12,15]$. Analogous effects are anticipated to be present in edge supported panels subjected to localized impulse loading, but the transmitted forces must also depend upon the thickness and strength of the faces which control the face stretching forces $[1,2,8]$.

After the beneficial FSI effect had been confirmed in water [2-8], numerous sandwich panel concepts for impulse and pressure mitigation have been explored [7-17]. Recent analytical [9] and numerical [18,19] assessments indicate the FSI effect is much weaker in air and only becomes significant when (i) the overpressure is high, (ii) the core crush strength is small and (iii) the face sheet exposed to the impulse has a very low mass (inertia) per unit area. Even so, recent experiments and confirmatory numerical simulations have shown that sandwich panels with thick, strong square honeycomb cores and thick face sheets still showed significantly reduced back face deflections compared to equivalent solid plates subjected to the same very high intensity (20-35 kPa.s) impulsive loads in air [1]. The thick face sheets were chosen in that study to ensure that the panel response was dominated by core failure modes for all the impulse levels investigated. The webs of the square honeycomb core were ideally oriented for supporting both the through thickness compressive and in-plane stretching loads encountered during the large scale 
bending of these edge supported panels and this appeared to have contributed significantly to the sandwich panel's beneficial response.

The through thickness (vertical) forces transmitted to supports are governed by the dynamic strength of the core which in turn depends upon the core relative density, the inertial strengthening of its structural members, and the strength (modified by strain rate hardening) of the material used for its construction $[13,17,20]$. As the core relative density is decreased, the quasi-static strength of cores made from trusses begins to exceed that of the honeycomb webs because of their higher buckling resistance [21, 22]. This has stimulated interest in the dynamic response of sandwich panel structures with lattice truss core topologies [23-27] even though they have limited stretch resistance [28-30]. Sandwich panels with pyramidal lattice topologies have been shown to be simple to manufacture [14,25-27] and were found to provide significant impulse and pressure mitigation when impulsively loaded in water [14,31].

Here, we investigate the localized impulse response of a pyramidal truss core sandwich panel with a wide core node to node spacing, slender trusses and a low core relative density of $2.3 \%$. The impulse was created by the detonation of a small explosive charge placed a small distance above the panel center. The incident specific impulse was varied from 1.5 to $7.6 \mathrm{kPa}$.s by changing the standoff distance between the charge center and the front face of the panel. The panels were made from a ductile stainless steel and the practical consequence of reducing the sandwich panel face sheet thickness (in an attempt to induce an FSI effect) upon the overall panel behavior has been investigated. The panel responses are also compared to those of monolithic solid plates of equivalent areal density. A decoupled finite element model has been used to computationally investigate the dynamic response of the panels. It predicts the panel deformations well and is used to analyze the dynamic deformation time sequence and the core failure mechanisms. The study shows that efforts to use thin face sheets to exploit FSI benefits are constrained by dynamic fracture of the front face and that this failure mode is in part a consequence of the high strength of the inertially stabilized trusses. Even though the pyramidal lattice core offers little in-plane stretch resistance, and the FSI effect is negligible, the sandwich panels are still found to suffer slightly smaller back face deflections and to transmit significantly reduced vertical forces compared to equivalent mass per unit area monolithic plates. 


\section{Sandwich panel design and fabrication}

A pyramidal lattice core with a relative density of $2.3 \%$ was fabricated from perforated $1.9 \mathrm{~mm}$ thick AL6XN (a super-austenitic stainless steel) cold rolled and annealed sheet [32]. The perforation pattern was made using a diamond shaped punch with $60^{\circ}$ and $120^{\circ}$ included angles as shown in Fig. 1. The perforated sheets were press brake formed using a 70 degree die angle to create a pyramidal truss structure whose unit cell is shown in Figure 2(a). The inter-nodal spacing was $\sim 35 \mathrm{~mm}$ and the core (out-ofplane) height was $25 \mathrm{~mm}$. The core was bonded to AL6XN face sheets with thicknesses of $0.76,1.52$ or $1.9 \mathrm{~mm}$ by laser welding to create the sandwich panels as shown in Fig 2 (a). A cross-section of a laser welded joint depicting the face sheet and truss core attachment node is shown in Fig. 2c, which illustrates the depth of penetration of the laser weld and the heat affected zone.

The localized impulse response of $0.61 \mathrm{~m} \times 0.61 \mathrm{~m}$ edge clamped test panels has been investigated. To ensure adequate side restraint, the panel edges were filled with an epoxy polymer (Crosslink Technologies CLR1061 resin and CLH6930 hardener), Fig2b. This was allowed to cure for 24 hours and a $19 \mathrm{~mm}$ diameter hole pattern was water-jet cut in each of the sandwich panels and the equal mass solid plates. The AL6XN alloy used for the study has high ductility and significant strain and strain rate hardening characteristics making it well suited for dynamic loading applications [33]. The alloy has an elastic modulus of 200GPa, a 0.2\% offset yield strength of $410 \mathrm{MPa}$, a density of $8060 \mathrm{~kg} / \mathrm{m}^{3}$ and a ductility up to $\sim 40 \%$ (failure strain).

\section{Impulse loading facility}

The test structures were impulsively loaded using the panel support system shown in Figure 3. The panels were mounted horizontally and bolted onto a $38 \mathrm{~mm}$ thick plate resting on I-beam supports along all four edges. A picture frame arrangement was used for edge clamping, and provided a $0.41 \mathrm{~m}$ x $0.41 \mathrm{~m}$ exposure area to the impulse. The localized impulse was created by the detonation of a $150 \mathrm{~g}$ spherical C-4 explosive that was pressed to fill the interior volume of a $57 \mathrm{~mm}$ inner diameter polyethylene sphere with a $1.5 \mathrm{~mm}$ shell thickness, Fig. 3. This explosive contains $91 \mathrm{wt} \%$ of RDX 
(cyclotrimethylene trinitramine) with the remainder consisting of a plasticizer and binder. It has a detonation velocity of approximately $8,000 \mathrm{~m} / \mathrm{s}$ [34]. The charge was edge detonated with a Daveydet detonator [35] slightly buried in the surface of the explosive furthest from the test structure, Fig 4.

Experiments were performed to independently investigate the effects of (i) the standoff distance between the explosive's location and the target test panel and (ii) the sandwich panel face sheet thickness upon the deformation and failure modes of the sandwich panels and their equivalent monolithic plates. For the variable standoff distance series of experiments, panels with a face sheet thickness of $1.52 \mathrm{~mm}$ were tested at standoff distances of 20,15 and $7.5 \mathrm{~cm}$ from the center of the spherical explosive charge to the top surface of the panels. To study the effect of the face sheet thickness $\left(t_{f}\right)$, panels with thicknesses of $0.76,1.52$ and $1.90 \mathrm{~mm}$ were tested at a fixed $15 \mathrm{~cm}$ stand-off distance (again measured form the charge center to the front face). The panels were sectioned after testing and their deformation profiles measured and photographed. A blast simulation code [36] developed by the U.S. Army Corps of Engineers was used to estimate the impulse loading corresponding to the test parameters (i.e. explosive material, charge weight and standoff distances) used in the experiments. The incident impulse varied in intensity over the plate surface and we report values for the peak impulse directly below the center of the test charge at the plate surface.

\section{Experimental Results}

Figure 5 shows the front and back of a panel with the thinnest face sheet thickness $(0.76 \mathrm{~mm})$ tested at the $15 \mathrm{~cm}$ standoff. In this instance, in addition to dishing of the deformable region inside of the clamped edges, tearing of the front face around each of the face-sheet, pyramidal core nodal attachments is observed (Fig. 5a). Careful examination shows that the trusses partially collapsed but by less than the distance of front face movement. As a result, many of the core nodes protrude above the deformed and partially fractured front face sheet. The back face of this sandwich panel is shown in Fig. 5b where it is seen that although the back face too underwent a significant permanent bending (and stretching) deformation, it did so without fracturing the (back) surface. The back surface also locally deformed at the nodes connecting it to the core, presumably as a 
result of the compressive loads transmitted by the trusses to the back supporting face. It appears that the impulse imparted to the front face causes it to move away from the explosion at a velocity outpacing the dynamic crush rate of the core and the large differential displacements then result in front face sheet fracture.

The deformation of the solid (1.9 mm thick) equivalent AL6XN plate after testing with an identical test charge at the same $15 \mathrm{~cm}$ standoff distance is shown in Figures 6 . This panel suffered a similar back face deflection to the sandwich panel and showed no evidence of incipient rupture.

Figure 7 shows the effect varying the standoff distance on the deformation response of sandwich panels with a thicker $(1.52 \mathrm{~mm})$ face sheet. The panels have been sectioned and Fig. 7 shows $1 / 4$ sections to allow comparison of the core deformation and face sheet stretching along a mid-plane. At the longest standoff of $20 \mathrm{~cm}$ (corresponding to an incident specific impulse of $1.5 \mathrm{kPa} . \mathrm{s}$ ), Fig. 7 (a), the panel suffered a significant center displacement but the core was not permanently crushed. As the impulse loading was increased (by decreasing the standoff), truss buckling and core crushing was observed and increased towards the center of the panel, Figs. 7 (b and c). At the closest standoff, Fig. 7(c), partial tearing of the front face sheet can be seen. Evidence of core shear can also be observed near the clamped edges due to differential stretching of the top and bottom face sheets. Two of the trusses of pyramidal core unit cell in this vicinity are clearly in tension while the other two are in compression and have plastically buckled.

In Fig. 8 (a), the experimental center displacements of the front and back surfaces of the sandwich panels and equivalent weight solid plates, normalized by the half-span of the edge clamped plate $(L)$ are plotted as a function of the normalized impulse ( $\bar{I}$ ) Given by;

$$
\bar{I}=I / M \sqrt{\sigma_{y} / \rho}
$$

where, $I$ is the imparted impulse, $M$ the mass per unit area of the sandwich panel (or equivalent weight solid plate), $\sigma_{y}$ the yield strength, and $\rho$ the density of the material. The plot shows that based on a center displacement comparison, the sandwich panel back face performed only slightly better than the equivalent weight (3.4 mm thick) solid plate. Figure 8 (b) shows the impulse dependence of the pyramidal core compression and the change in sandwich panel face sheet separation. As the incident impulse increased (i.e. by decreasing the standoff from $20 \mathrm{~cm}$ to $7.5 \mathrm{~cm}$ ), significantly more core crushing occurred. 
For the two longer standoff distances $15 \mathrm{~cm}$ and $20 \mathrm{~cm}$, the core and the front face sheet remained intact. However, at the shortest standoff distance $(7.5 \mathrm{~cm})$, the higher specific impulse resulted in penetration of the front face sheet by the core.

The effect of varying the face sheet thickness on the sandwich panel response for a constant impulse of $2.3 \mathrm{kPa}$.s is illustrated in Figure 9. As the face sheet thickness was reduced, significantly more deformation was observed for both the front and back face sheets at the panel center. Figure 9(c) indicates that core crushing at the panel center occurred by plastic buckling of the pyramidal truss members. Here too, core shear can be observed closer to the clamped edges, with two of the trusses of the pyramidal core unit cell in tension and the other two in compression (they had plastically buckled). As the face sheet thickness, and thus mass per unit area, $m_{f}$, was reduced for a fixed impulse, $I$, momentum conservation requires the front face to move away from the blast at higher velocities $\left(v_{f}=I / m_{f}\right)$. This appears to then allow insufficient time for core crushing to occur (the core is inertially stabilized). Significant front face sheet tearing then occurs with the pyramidal core node punching through the face sheet. Even though significant front face tearing occurs, no perforation of the back face was evident.

The front and back face deflections of the sandwich are plotted against panel areal density in Figure 10(a). It can be seen that the deflections decrease rapidly with increase in panel mass per unit area and that there is a slightly reduced back face deflection (compared to the solid plate) for the thicker face panel designs. The core compression at the panel center and the change in face sheet separation are plotted as a function of the front face sheet areal density in Figure 10 (b). If face sheet tearing does not occur, a monotonic decrease in core compression with increasing face sheet thickness (i.e. areal density) is anticipated. This is observed for the sandwich panels with the two thickest face sheets $(1.5 \mathrm{~mm}$ and $1.9 \mathrm{~mm})$. However, it is apparent that for the pyramidal core cell size used here (35 mm), there appears to be a limit (just below a thickness of $1.5 \mathrm{~mm}$ ) below which the face sheet thickness cannot be reduced without triggering face sheet tearing and some loss of face sheet stretch resistance. We note that tearing at close standoff distances was more localized (to the panel center) than at longer stand-offs using thinner faces.

\section{Finite Element Simulations}


Three-dimensional finite-element calculations were performed to simulate the dynamic response of the sandwich panels and identify the temporal sequence of panel deformations. First, using a C-4 charge mass of 150g, and the standoff distances used for the experiments, the applied pressure distribution on the surface of the panels was calculated using the ConWep code [36]. The procedure utilized by this code for determining the blast pressure spatial and temporal profiles has been described elsewhere [1]. The pressure fields were then used in a decoupled fluid-structure analysis of the panel response. Briefly, the calculated time dependent, non-uniformly distributed pressure was applied to the top surface of the sandwich panels, and the ABAQUS/Explicit [37] finite element code was employed to analyze the structural performance. Due to the symmetry of the structure, only one quarter of the panel was analyzed as depicted in Figure 11(a). Symmetric boundary conditions were applied to the inner edges of sandwich face sheets. The support structure was simply modeled as a rigid wall, and the outer edges of sandwich face sheets were clamped to the rigid wall. The truss members were tied to the face sheets at their connections. The eventual contacts between buckled truss members and the face sheets during dynamic core crushing were taken into account in the model. It was assumed that the contacts were frictionless. The faces of sandwich panels were meshed using four-node shell elements with finite membrane strains. Five integration points with Simpson's integration rule were used in each shell element. These elements allow large rotations and finite membrane deformation. The truss members of the sandwich panels were fully meshed using 4-node linear tetrahedron elements as shown in Fig. 11(b). Additional studies indicated that the current meshing scheme yielded results with a numerical error in maximum deflection of less than $1 \%$.

The test sandwich panels were made from a superaustenitic stainless steel alloy having a density of $8060 \mathrm{~kg} / \mathrm{m}^{3}$ and a Poisson ratio of 0.3 . Mises criterion was used to model yielding of the material. A strain-rate dependent function was utilized to describe the true stress versus true strain relation as 


$$
\sigma=\left\{\begin{array}{ll}
E \varepsilon & \varepsilon \leq \frac{\sigma_{Y}}{E}\left(1+\left(\dot{\varepsilon}_{p} / \dot{\varepsilon}_{0}\right)^{m}\right) \\
\sigma_{Y}\left(1+\left(\dot{\varepsilon}_{p} / \dot{\varepsilon}_{0}\right)^{m}\right)+E_{t}\left(\varepsilon-\frac{\sigma_{Y}}{E}\left(1+\left(\dot{\varepsilon}_{p} / \dot{\varepsilon}_{0}\right)^{m}\right)\right) & \varepsilon>\frac{\sigma_{Y}}{E}\left(1+\left(\dot{\varepsilon}_{p} / \dot{\varepsilon}_{0}\right)^{m}\right)^{m}
\end{array} .\right.
$$

Here, $E=200 G P a$ (Young's modulus), $\sigma_{\mathrm{y}}=410 \mathrm{MPa}$ (initial yield strength) and $E_{t}=2.0 \mathrm{GPa}$ (the tangent modulus). Dynamic measurements on stainless steels are well represented using the values $\dot{\varepsilon}_{0}=4,916 \mathrm{~s}^{-1}$ and $m=0.154[33,38]$. No failure criterion was included in the calculations, so the computational model fails to predict the penetration of truss members into the top face and any other top face sheet fracture mode.

Additional three-dimensional finite element calculations were performed for equivalent solid plates. The solid plates were fully meshed using eight-node linear brick elements with reduced integration. The material properties and boundary conditions were the same as those imposed for the sandwich panels.

\section{Finite Element Results}

Figure 12 shows the time deformation sequence of a quarter symmetry sandwich panel with a face sheet thickness of $1.52 \mathrm{~mm}$ at a standoff $7.5 \mathrm{~cm}$. Fig. 12 (a) shows the panel at time, $\mathrm{t}=0$ when the impulse is imparted to the sandwich panel. At $\mathrm{t}=0.1 \mathrm{~ms}$ increased deformations and plastic strains in the two face sheets and pyramidal trusses closer to the center of the panel are observed. At $t=0.5 \mathrm{~ms}$, the strains appear to be distributed over a wider area while further deformation occurs. At $\mathrm{t}=2 \mathrm{~ms}$, the plastic strain levels appear to diminish due to the spring back of the panel towards its final deformed shape.

Figure 13 shows the calculated center deflections of the sandwich panel front and back faces along with those of the equivalent weight solid plate as a function of time for three standoff distances. The initial rapid movement away from the blast of each of the surfaces and the subsequent oscillatory nature of the time response indicate the highly dynamic motion of the sandwich and solid plates. The deformed panels are eventually brought to rest after spring back. In all three standoff distance cases, the front face of the 
sandwich panel appears to take off at a higher velocity than the back face. The take-off velocity of the equivalent weight solid plate lies between these limits. The low back face "take off" velocities resulted from the need to communicate the movement of the front face through the dynamically crushing core. By comparing the initial slopes of the deflection-time plots (Figs. 13(a-c)), it is evident that the test panels (sandwich sample or solid plate) subjected to the highest impulse (those at closest standoff), move the most rapidly in a direction away from the explosive charge. In this case, the solid plate's initial velocity was $\sim 110 \mathrm{~m} / \mathrm{s}$ falling to $60 \mathrm{~m} / \mathrm{s}$ at a stand-off of $15 \mathrm{~cm}$ and $40 \mathrm{~m} / \mathrm{s}$ at $20 \mathrm{~cm}$.

Figure 14 shows the finite element simulation calculated center displacements of the front and back surfaces of the sandwich panels and equivalent weight solid plates, normalized by the half-span of the edge clamped plate $(L)$ plotted as a function of the normalized impulse, $\bar{I}$.The plot shows good agreement with the experimental results (Fig.8a) at the lower impulses (corresponding the 200 and $150 \mathrm{~mm}$ standoff distances) but at higher impulses, the FEM analysis under predicts the experimental result, significantly so for the front face. This appears to be a result of a fracture criterion not been incorporated in to the FEM analysis, since as Figure 7(c) illustrated, severe localized tearing of the front face at the normalized impulse of 1.2 corresponding to the closest standoff distance of $75 \mathrm{~mm}$ occurred. In all cases, the simulations indicate that the sandwich panel performs only marginally better than the solid plate, with the back face deflections being slightly less than those of the solid plates.

The time evolution of the panel response with thin front and back face sheets $\left(t_{\mathrm{f}}=\right.$ $0.76 \mathrm{~mm}$ ) is shown in Figure 15. Significant localized deformation of the front face in between the nodes of the pyramidal core is observed over the deformation period. As before, the plastic strain contours indicate that the panel dynamically deforms to a peak displacement (and accompanying strain levels) before reaching a steady-state deformed shape.

The comparisons of the calculated finite element center displacements for the front face, back face and the solid plates are shown in Figure 16 for three face sheet thicknesses of 1.9, 1.52 and $0.76 \mathrm{~mm}$ respectively (and their corresponding equivalent weight solid plates) for a constant imparted specific impulse of $2.3 \mathrm{kPa}$.s. It can be seen that the panels with the thinnest (lightest) face sheets had the highest initial velocity 
( $200 \mathrm{~m} / \mathrm{s}$ ). Comparison of the final back face and solid plate displacements indicates a very slight benefit of the sandwich panel, but this advantage disappears for extremely thin face sheet sandwich panels. The experimental and calculated normalized center displacements of the panels are plotted against the areal densities of the overall panels in Figure 17. A monotonically decreasing trend of the center deflections with increasing panel weight is observed and reasonable agreement is again observed between the FEM and experimental results.

\section{Discussion}

The series of experiments presented above indicate that edge clamped sandwich panel construction provides only slightly reduced back face deflections compared to equivalent solid plates when both are impulsively loaded by an air blast. These observations are consistent with the absence of a significant FSI effect. Efforts to create such an effect by reducing the inertia of the front face and using a soft core panel have been foiled by face sheet perforation. This perforation increased in severity as either the face sheet areal density is reduced or the incident impulse is increased such that the front face initial speed increased towards $200 \mathrm{~m} / \mathrm{s}$. This phenomenon arises from significant inertial strengthening of the core trusses and can be better understood by schematically illustrating the forces experienced by the face sheets and pyramidal core.

Figure 18 shows the top view of a localized front face failure at the center of a panel and corresponding schematic top and side views of the sandwich panel. For the edge clamped panel studied here, large scale bending deflections require both the front and back face sheets to support large tensile (stretching) forces. In the vicinity of the center of the panel (the area closest to the blast), the pyramidal truss elements are subject to compressive forces and resultant truss buckling. Between each face sheet - pyramidal core node, the localized stretching results in eventual failure of the front face sheet. Figure 19 schematically illustrates how tearing occurs as the face sheet thickness is reduced. For the thickest face sheets $t=t_{1}$, Fig19 (a), the tensile stress in the face sheet is the lowest due to the larger cross sectional area of the face sheet available to sustain the applied loads. As the face sheet thickness is decreased to $t=t_{3}$, the cross-sectional area decreases too, resulting in higher face sheet stresses (under the same impulse loading 
condition). Because the nodes are initially unable to rotate towards each other, the high stresses in the faces result in significant ductile stretching and then tearing of the face sheet. Four tears occur from each node with the tears propagating along the trusses (these trusses form a square pattern viewed in projection from above). This tearing pattern is a result of contact (and constraint) of the face sheet with the underlying core members.

It is instructive to examine the predicted reaction forces of the sandwich panels under the boundary conditions used in the experiment. This enables estimation of the force components transmitted to the panel supports. The finite element simulations enable the horizontal and vertical reaction forces of both the front and back faces of the sandwich panels to be calculated at the clamped panel edges (Fig. 20) and compared to those of the solid plate. Figure 21 shows the temporal response of the vertical and horizontal reaction forces at standoff distances of 7.5, 15 and $20 \mathrm{~cm}$ for a sandwich panel with a face sheet thickness $\mathrm{t}=1.52 \mathrm{~mm}$ and an equivalent weight solid plate with thickness of $3.4 \mathrm{~mm}$. The peak transmitted force variation with standoff is plotted in Figure 22. At each standoff, the sum of the front and back face transmitted forces in the vertical direction are significantly less than that transmitted by the solid plate. A monotonically increasing transmitted load with decreasing standoff trend is observed for the solid plate whereas a similar trend is not observed for the sandwich faces. Such an effect is not seen for the stretching dominated horizontal force and no clear trend with standoff distance is observed for either the sandwich panel or solid plate. The back face, which always deformed less than the front face (closest to the impulse) did suffer a lower stretching force than the front face.

The effect of a varying face sheet thickness on the reaction force was also calculated (for a constant standoff distance of $15 \mathrm{~cm}$ ). Figure 23 shows the temporal responses for components of force. The peak transmitted forces as a function of the face sheet thickness are plotted in Figure 24. An insignificant dependence on face sheet thickness is observed for the sandwich panel vertical reaction force. The solid plate appeared to transmit much larger peak vertical reaction forces than the sandwich panel front and back faces. It is again evident that higher horizontal forces were transmitted through the front face than the back face sheet, and the thicker face sheet sandwich panels 
transmitted much higher horizontal forces than the thinner face sheet panels to the edge supports.

\section{Conclusions}

Sandwich panels made of a ductile stainless steel have been fabricated by a perforated plate bending/laser welding method and their response to small scale explosive loading has been investigated.

1. Panels tested in air exhibit no evidence of the beneficial FSI effect observed in under water impulsive loading, even when the face sheet thicknesses were reduced to the tearing limit. This result is consistent with recent analysis of the interaction of air propagated shocks with solid plates of varied inertia.

2. The back face deflections of the sandwich panels was only marginally less than that of equivalent solid plates consistent with a response that was governed by face sheet stretching. For the thin, weak core sandwich structures tested here, the sandwich effect appears to have been insufficient to reduce deflections in the large deflection regime of interest.

3. A decoupled finite element model has been used to computationally investigate the dynamic response of the panels. It predicts panel deformations well and is used to identify the deformation time sequence and the face sheet and core failure mechanisms. The computational part of the study shows that efforts to use thin face sheets to exploit FSI benefits are constrained by dynamic fracture of the front face and that this failure mode is in part a consequence of the high strength of the inertially stabilized trusses.

4. Even though the pyramidal lattice core offers little in-plane stretch resistance, and the FSI effect is negligible during loading by air, the sandwich panels are found to transmit significantly smaller vertical component forces to the supports compared to equivalent monolithic plates.

\section{Acknowledgements}

Support from the Office of Naval Research through a Multidisciplinary University Research Initiative program on "Cellular materials concepts for force protection", Prime Award No. N00014-07-1-0764 is gratefully acknowledged. The program manager was Dr David Shifler. 


\section{References:}

[1] K.P. Dharmasena, H.N.G. Wadley, Z. Xue and J.W. Hutchinson, "Mechanical response of metallic honeycomb sandwich panel structures to high intensity dynamic loading”, International Journal of Impact Engineering, 35 (2008) 1102-1114.

[2]. Z. Wei, V.S. Deshpande, A.G. Evans, K.P. Dharmasena , D.T. Queheillalt, H.N.G. Wadley, Y.Murty, R.K. Elzey, P.Dudt, Y.Chen, D.Knight and K.Kiddy. The resistance of metallic plates to localized impulse. Journal of Mechanics and Physics of Solids 56 (2008)2074-2091.

[3]. Fleck, N.A., Deshpande, V.S., 2004. The resistance of clamped sandwich beams to shock loading. J. Appl. Mech. 71, 386-401.

[4]. Hutchinson, J. W., and Xue, Z., 2005, "Metal Sandwich Plates Optimized for Pressure Impulses,” Int. J. Mech. Sci., 47, pp. 545-569.

[5]. Rabczuk, T., Kim, J.Y., Samaniego, E., Belytschko, T., 2004. Homogenization of sandwich structures. Int. J. Numer. Meth. Eng. 61, 1009-1027

[6]. Rathbun, H.J., Radford, D.D., Xue, Z., He, M.Y., Yang, J., Deshpande, V., Fleck, N.A., Hutchinson, J.W., Zok, F.W., Evans, A.G., 2006. Performance of metallic honeycomb-core sandwich beams under shock loading. Int. J. Solids Struct. 43, 17461763.

[7]. Xue, Z., Hutchinson, J.W., 2004. A comparative study of impulse-resistant metallic sandwich plates. Int. J. Impact Eng. 30, 1283-1305.

[8] Liang Y, Spuskanyuk AV, Flores SE, Hayhurst DR, Hutchinson JW, McMeeking RM and Evans AG. The response of metallic sandwich panels to water blast. Journal of Applied Mechanics 2007; 74:81-99.

[9]. A. Vaziri, J. W. Hutchinson. Metallic sandwich plates subject to intense air shocks. International Journal of Solids and Structures 2007;44(1):2021-2035.

[10]. Taylor, G. I., 1963, "The Pressure and Impulse of Submarine Explosion Waves on Plates," in The Scientific Papers of G.I. Taylor, Vol. III, Cambridge University Press, Cambridge, UK, pp. 287-303

[11]. Dharmasena KP, Queheillalt DT, Wadley HNG, Chen Y, Dudt P, Knight D, Wei Z and Evans AG. Dynamic response of a multilayer prismatic structure to impulsive loads incident from water. International Journal of Impact Engineering, 2009;36:632-643. 
[12]. Dharmasena KP, Queheillalt DT, Wadley HNG, Dudt P, Chen Y, Knight D, Evans AG and Deshpande VS, Dynamic Compression of Metallic Sandwich Structures During Planar Impulsive Loading in Water. Eur. J. Mechanics - A/Solids, Accepted (2009).

[13]. Wadley HNG, Dharmasena KP, Queheillalt DT, Chen Y, Dudt P, Knight D, Kiddy $\mathrm{K}$, Xue Z and Vaziri A. Dynamic compression of square honeycomb structures subjected to impulsive underwater loading. Journal of Mechanics of Materials and Structures, 2007; 10(2), 2025-2048.

[14]. Wadley HNG, Dharmasena KP, Chen Y, Dudt P, Knight D, Charette R and Kiddy $\mathrm{K}$. Compressive response of multilayered pyramidal lattices during underwater shock loading. International Journal of Impact Engineering, 2008; 35:1102-1114.

[15]. McShane GJ, Deshpande VS and Fleck NA. The underwater blast resistance of metallic sandwich beams with prismatic lattice cores. Journal of Applied Mechanics 2007; 74:352-364.

[16]. Deshpande VS and Fleck NA. One-dimensional response of sandwich plates to underwater shock loading. Journal of the Mechanics and Physics of Solids 2005; 53:2347-2383.

[17]. Mori LF, Lee S, Xue Z, Vaziri A, Queheillalt DT, Dharmasena K.P, Wadley HNG, Hutchinson JW and Espinosa HD. On the behavior of sandwich structure subjected to under water impulse loads. Journal of Mechanics of Materials and Structures 2007; 2(10), 1981-2006.

[18]. N. Kambouchev, L. Noels, R. Radovitzky. Compressibility effects on fluid structure interactions and their implications on the blast loading of structures. Journal of Applied Physics 2006;100(6):063519.

[19] N. Kambouchev, L. Noels, R. Radovitzky. Fluid-structure interaction effects in the loading of free-standing plates by uniform shocks. Journal of Applied Mechanics 2007;74.

[20]. Xue Z, Hutchinson JW. Crush dynamics of square honeycomb sandwich cores. Int J. Numer. Methods Eng 2005; 65:2221-45.

[21]. Deshpande VS, Fleck NA. Int. J. Solids Struct. 38 (2001) p. 6275.

[22]. Deshpande VS, Fleck NA, Ashby MF. Effective properties of the octet-truss lattice material. Journal of the Mechanics and Physics of Solids 2001;49:1747-69.

[23]. H.N.G. Wadley, Multifunctional periodic cellular metals. Philosophical Transactions of the Royal Society A: Mathematical, Physical and Engineering Sciences 2006;364:31-68.

[24]. Evans AG, Hutchinson JW, Fleck NA, Ashby MF, Wadley HNG. The topological design of multifunctional cellular metals. Progress in Materials Science 2001;46:309-327. 
[25]. Kooistra GW, Wadley HNG. Lattice truss structures from expanded metal sheet. Materials and Design 28(2007), 507-514.

[26]. Queheillalt DT, Murty Y, Wadley HNG. Mechanical properties of an extruded pyramidal lattice truss sandwich structure, Scripta Materialia 58 (2008) 76-79.

[27]. Queheillat DT, Wadley HNG. Pyramidal lattice truss structures with hollow trusses, Materials Science and Engineering A 397 (2005) 132-137

[28]. Valdevit L, Hutchinson JW, Evans AG. Structurally optimized sandwich panels with prismatic cores. International Journal of Solids and Structures 2004;41:5105-5124.

[29].Zok FW, Rathbun H, He M, Ferri E, Mercer C, McMeeking RM, Evans AG. Structural performance of metallic sandwich panels with square honeycomb cores. Philosophical Magazine 2005;85:3207-3234.

[30]. Zok FW, Waltner SA, Wei Z, Rathbun HJ, McMeeking RM, Evans AG. A protocol for characterizing the structural performance of metallic sandwich panels: application to pyramidal truss cores. International Journal of Solids and Structures 2004;41:6249-6271.

[31]. Wei Z, Dharmasena KP, Wadley HNG and Evans AG. Analysis and interpretation of a test for characterizing the response of metallic sandwich panels to water blast. International Journal of Impact Engineering 2007; 34:1602-1618.

[32]. Metals Handbook. American Society of Metals, 1985

[33] Nemat-Nasser S, Guo WG, and Kihl DP, Thermomechanical response of AL-6XN stainless steel over a wide range of strain rates and temperatures, Journal of the Mechanics and Physics of Solids, 49, pp 1823-1846, 2001.

[34]. P. Cooper. Explosives Engineering, Wiley-VCH Interscience 1996.

[35]. http://www.daveybickford.com/catalogue/mines eng.htm (2009).

[36]. ConWep blast simulation software, U.S. Army Corps of Engineers, Vicksburg, MS.

[37]. ABAQUS/Explicit User Manual.

[38]. Stout MG, Follansbee PS, Strain rate sensitivity, strain hardening, and yield behavior of 304L stainless steel, Trans. ASME: J. Engineering Mater. Tech., 108, pp. 344-353, 1986. 


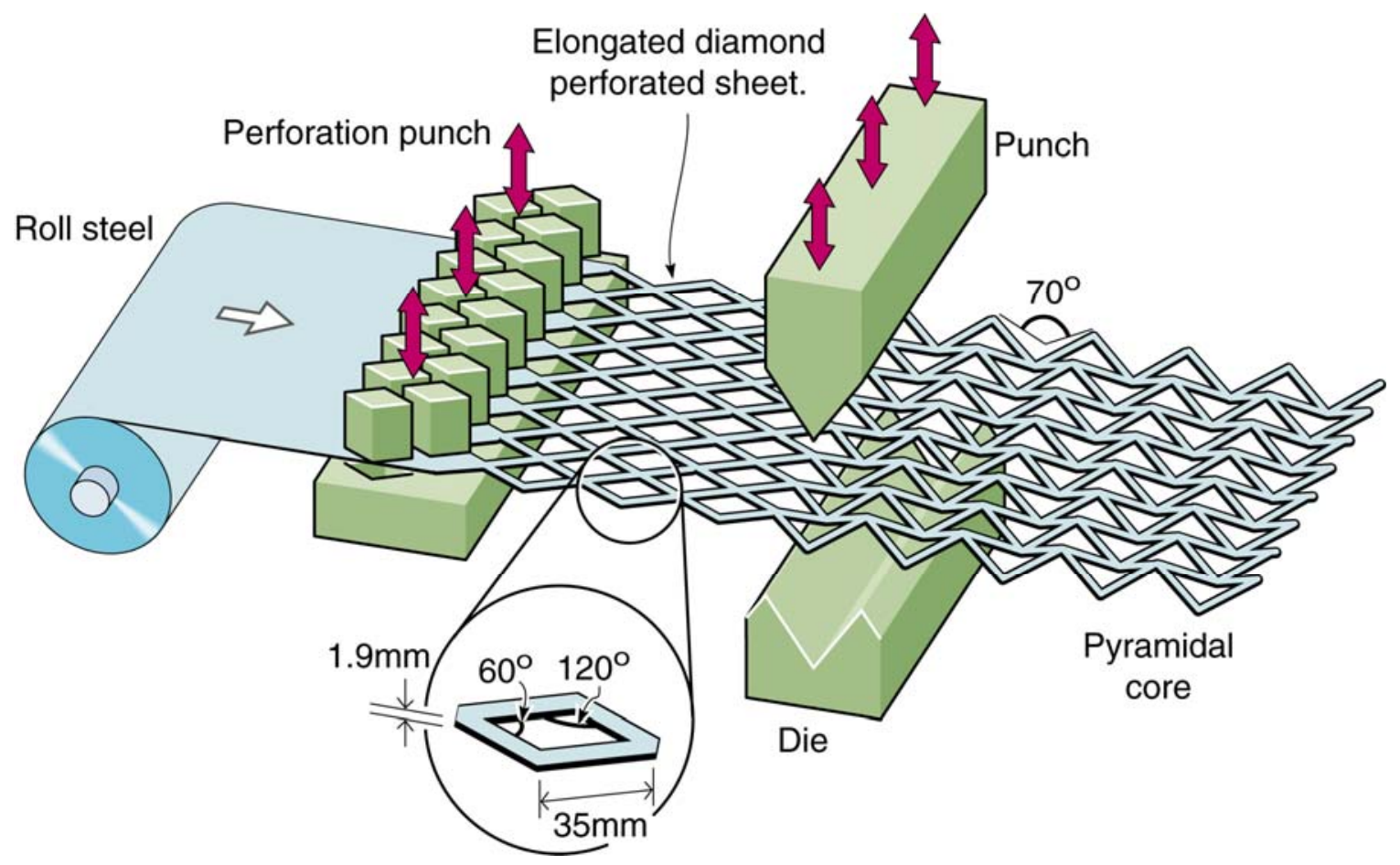

Figure 1 . The pyramidal truss core fabrication process. 
a) Panel assembly and unit cell

b) Test structure geometry
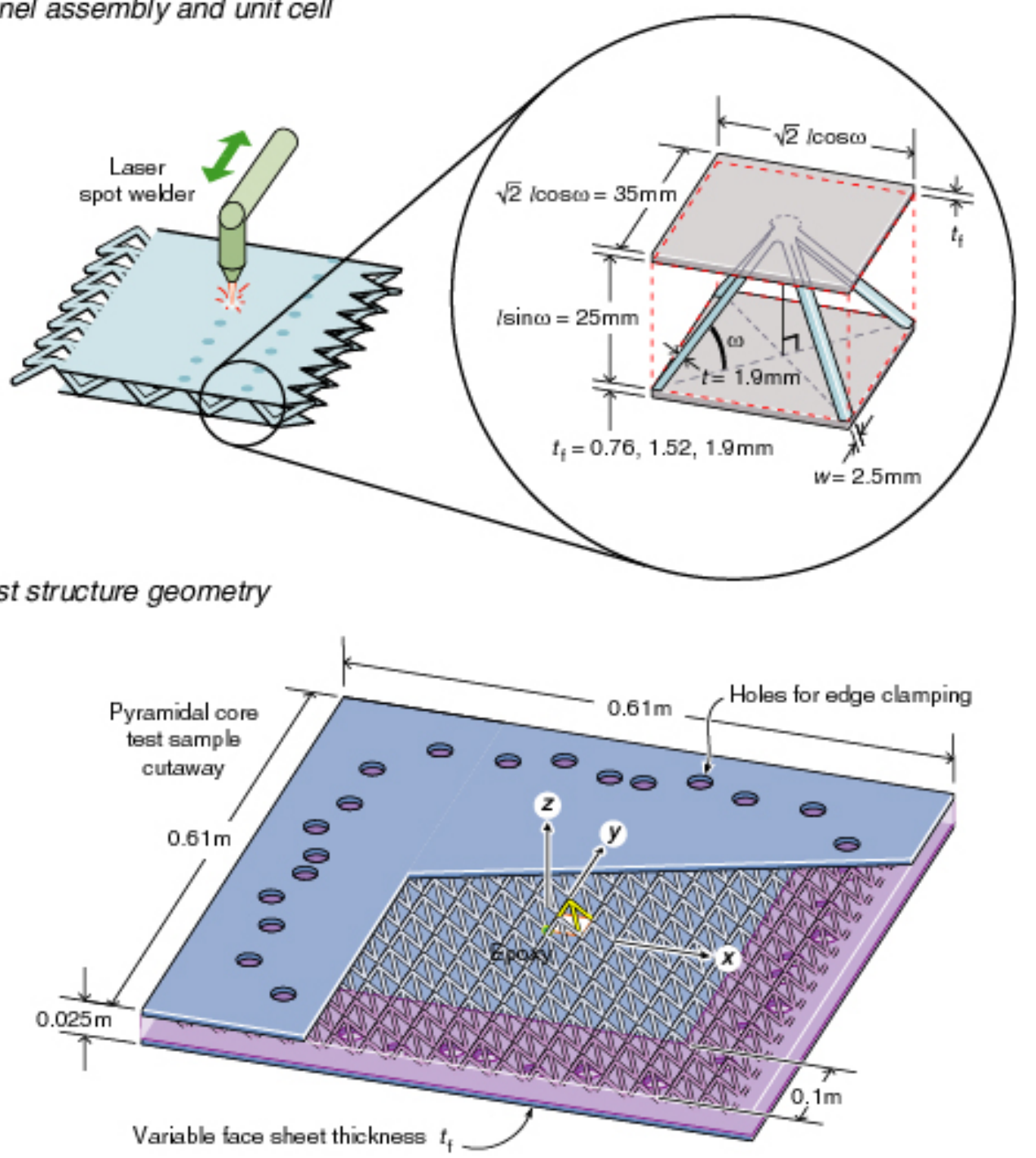

c) Laser welded face sheet - pyramidal truss core attachment cross-section and microstructure

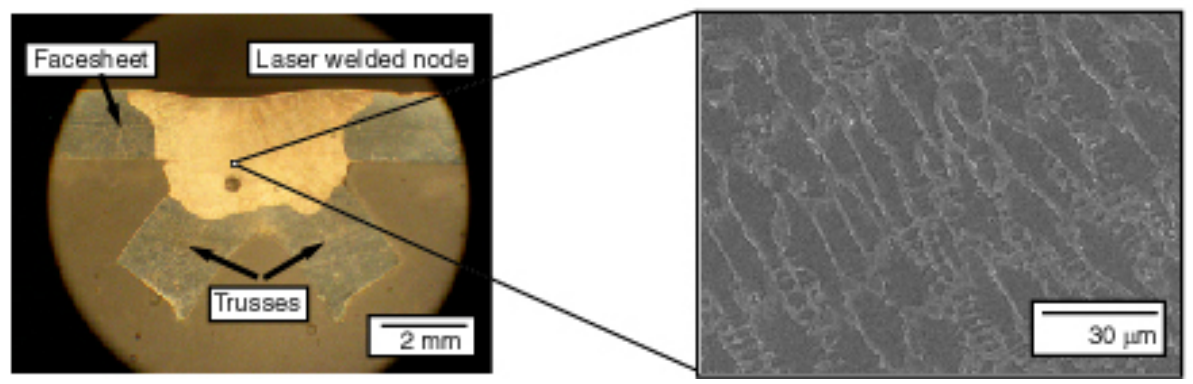

Figure 2(a) Laser welded face sheet attachment and pyramidal core unit cell. (b) Epoxy edge reinforced sandwich panel and (c) etched cross section and microstructure of a face sheet - truss node attachment. 


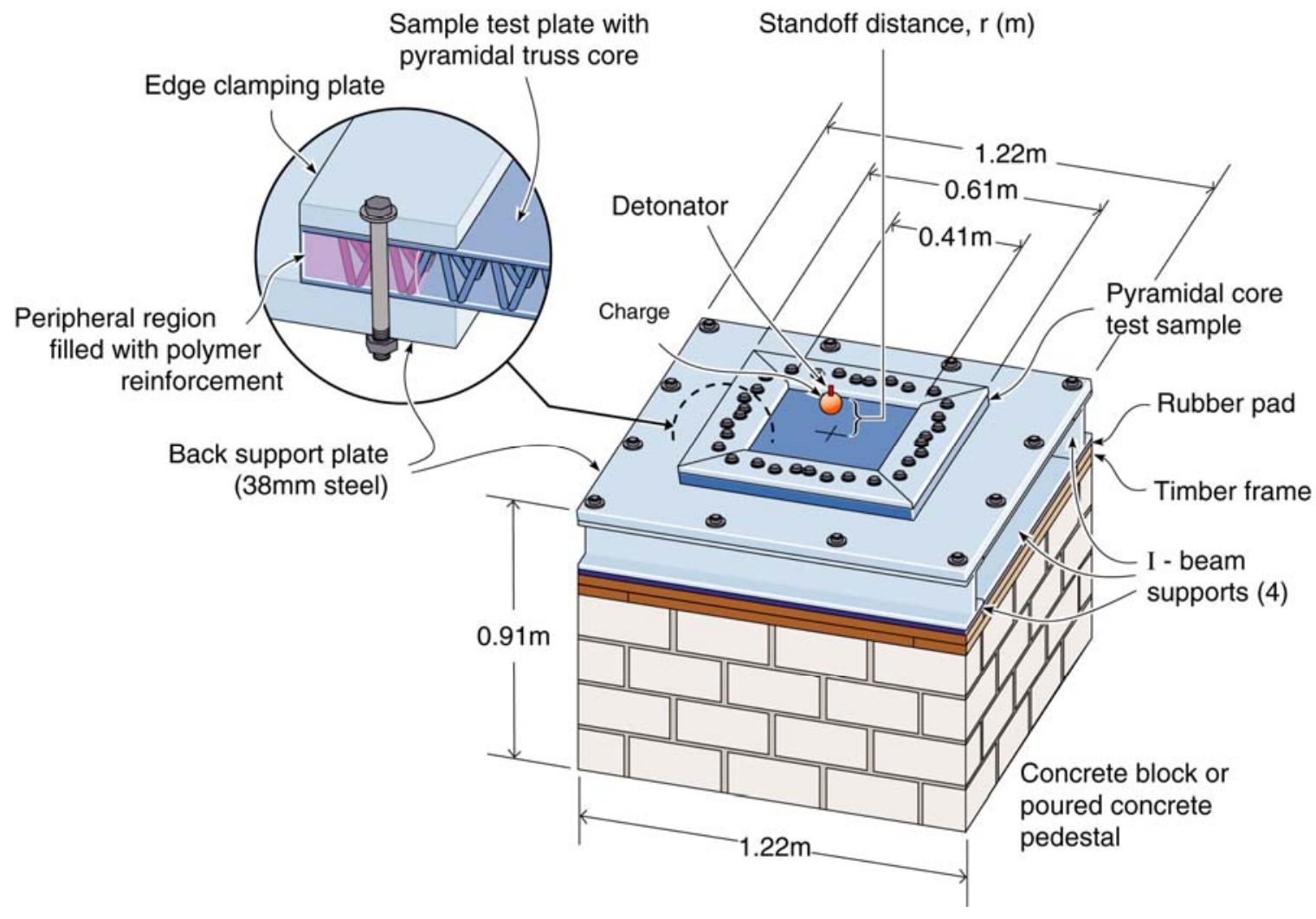

Figure 3. Schematic diagram of the air blast test geometry. 


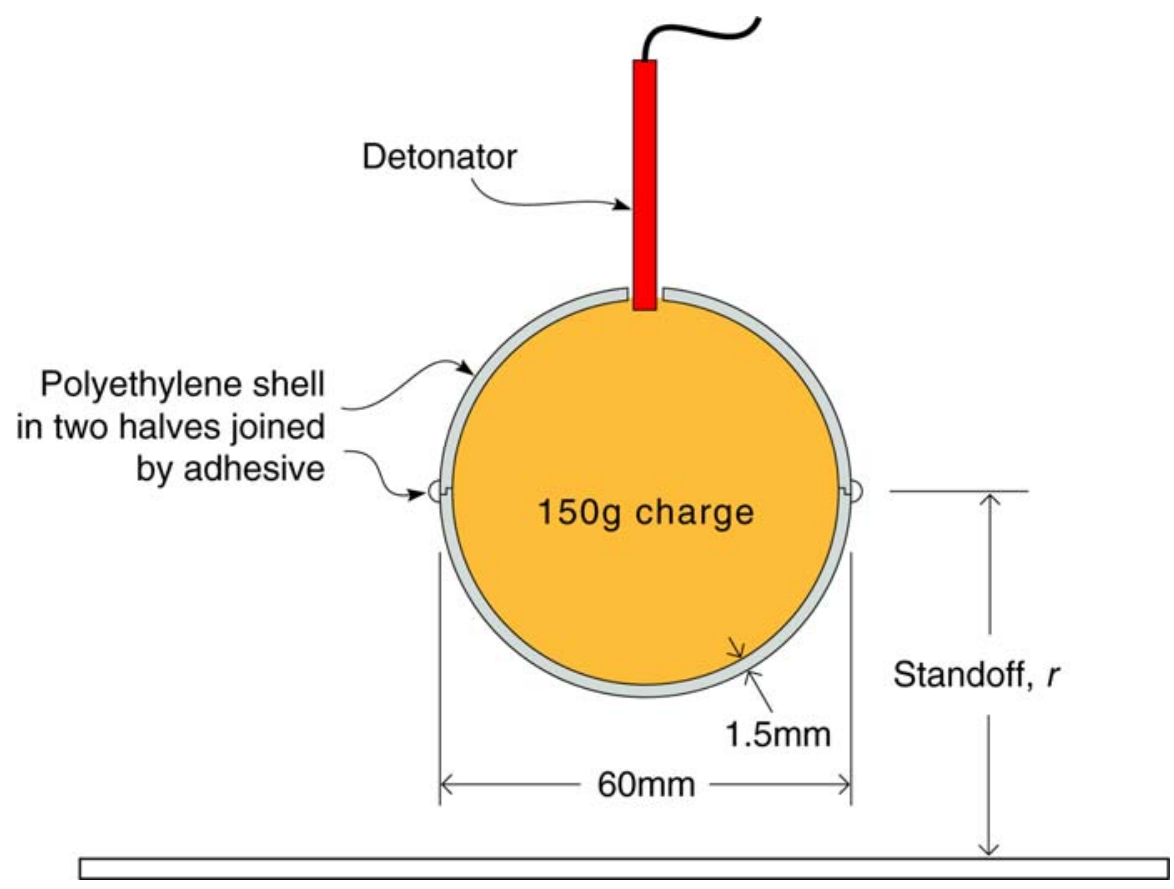

Figure 4 . The $150 \mathrm{~g}$ spherical test charge and detonation geometry. 

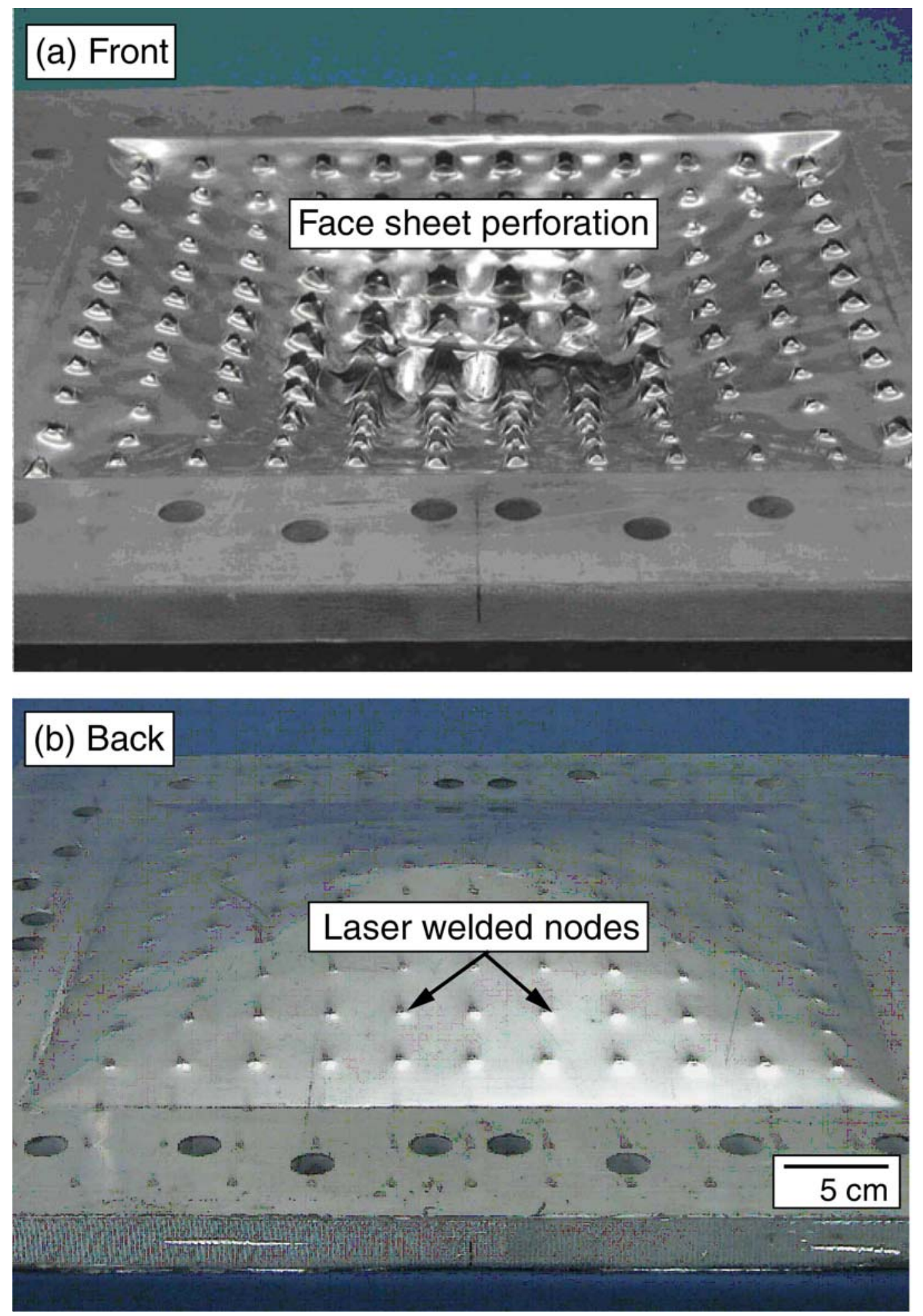

Figure 5(a). Front and (b) back surface of a sandwich panel with a $0.76 \mathrm{~mm}$ thick face sheet after testing. The standoff distance from charge center to front face was $0.15 \mathrm{~m}$. 


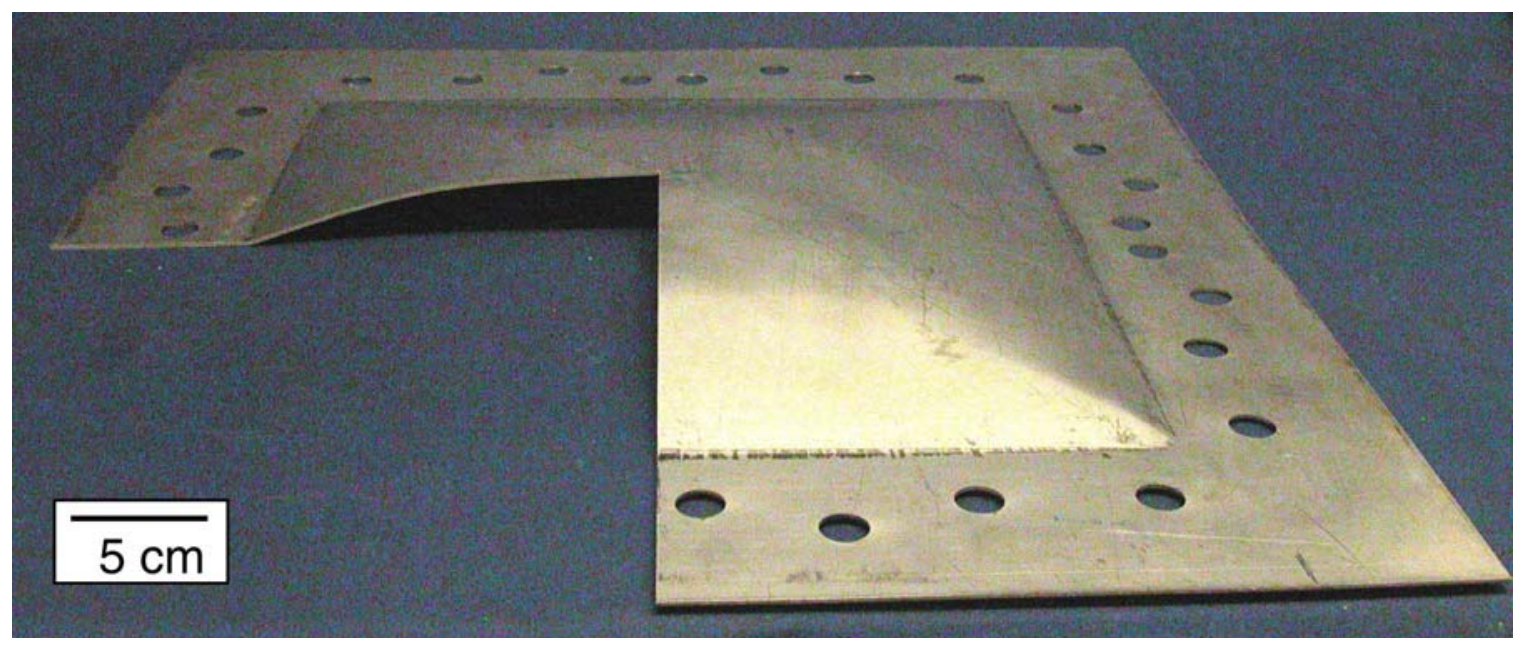

Figure 6. A $1.9 \mathrm{~mm}$ thick, AL6XN sheet (with the same areal density as the pyramidal core sandwich panel) after testing. The standoff distance was $0.15 \mathrm{~m}$
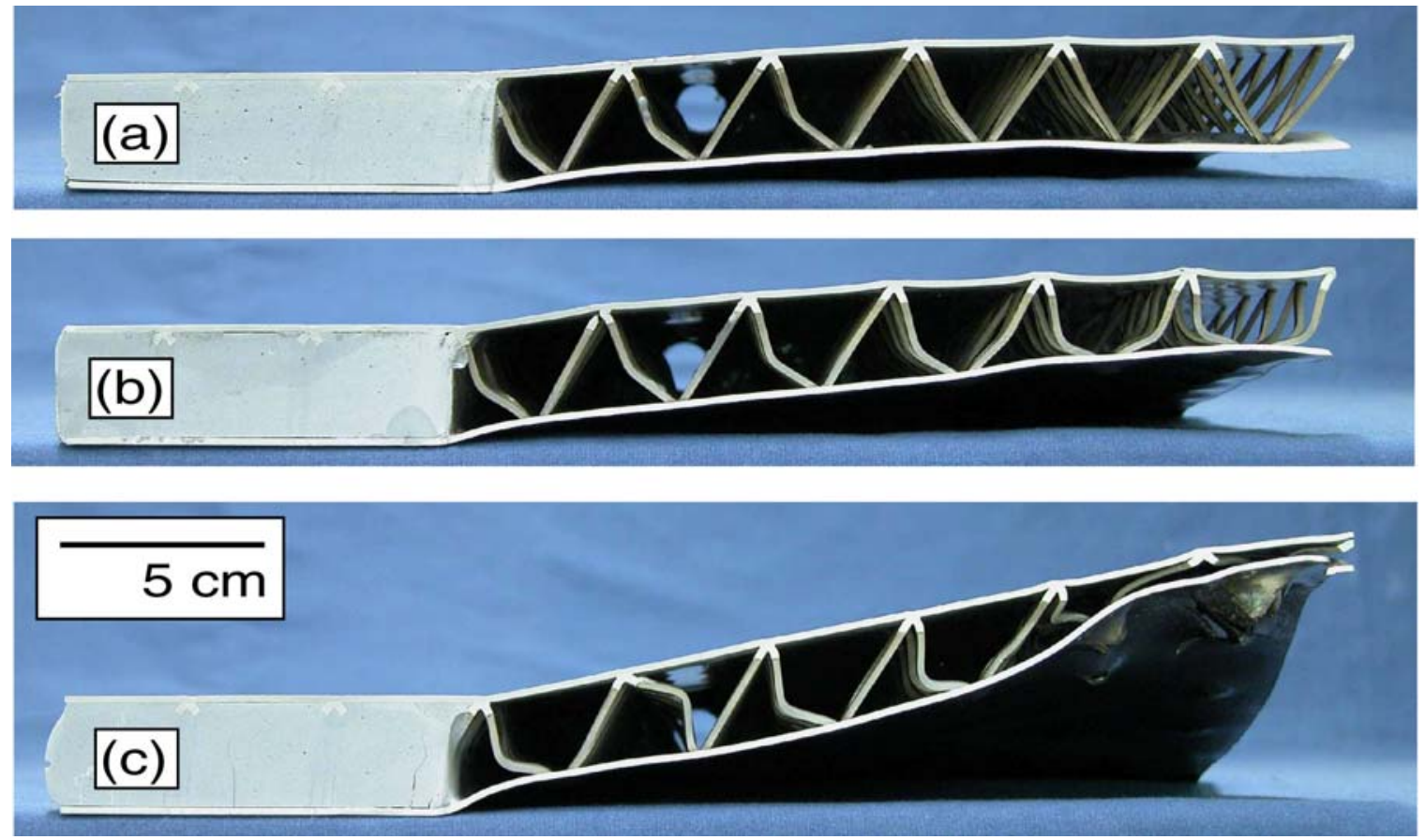
Figure 7. Effect of increasing the imparted impulse upon the deformation of a sandwich panel with a fixed face sheet thickness of $1.52 \mathrm{~mm}$. (a) Standoff $=0.20 \mathrm{~m}$, Impulse $=1.5$ kPa.s, (b) Standoff $=0.15 \mathrm{~m}$, Impulse $=2.3 \mathrm{kPa} . \mathrm{s}$ and (c) Standoff $=0.075 \mathrm{~m}$, Impulse $=$ 7.6 kPa.s. 

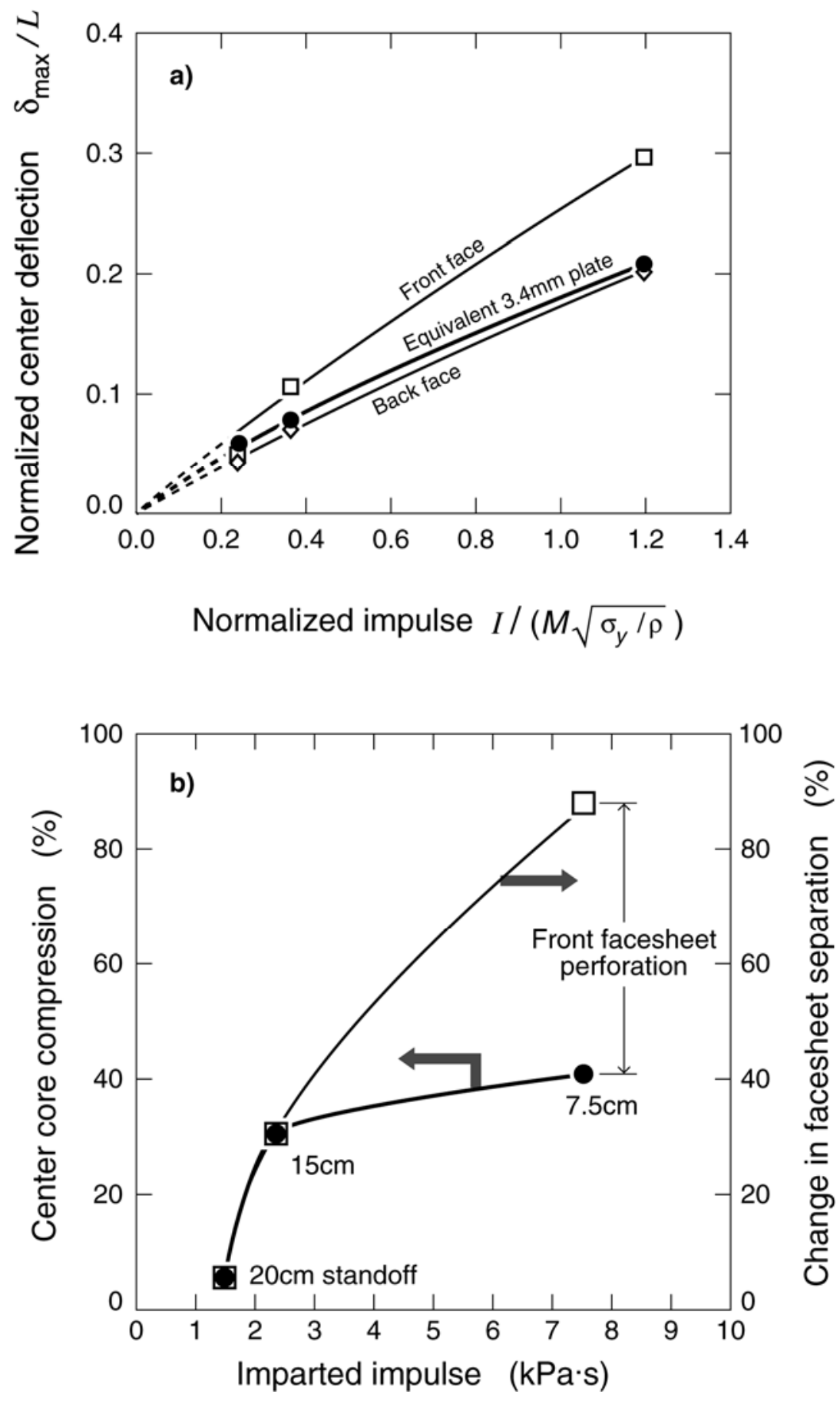

Figure 8. (a) Normalized center deflections for sandwich panel front and back faces with a thickness of $1.52 \mathrm{~mm}$, and the response of a $3.4 \mathrm{~mm}$ thick equivalent mass/unit area solid plate. (b) The pyramidal truss core permanent strain and change in sandwich panel face sheet separation with impulse. 

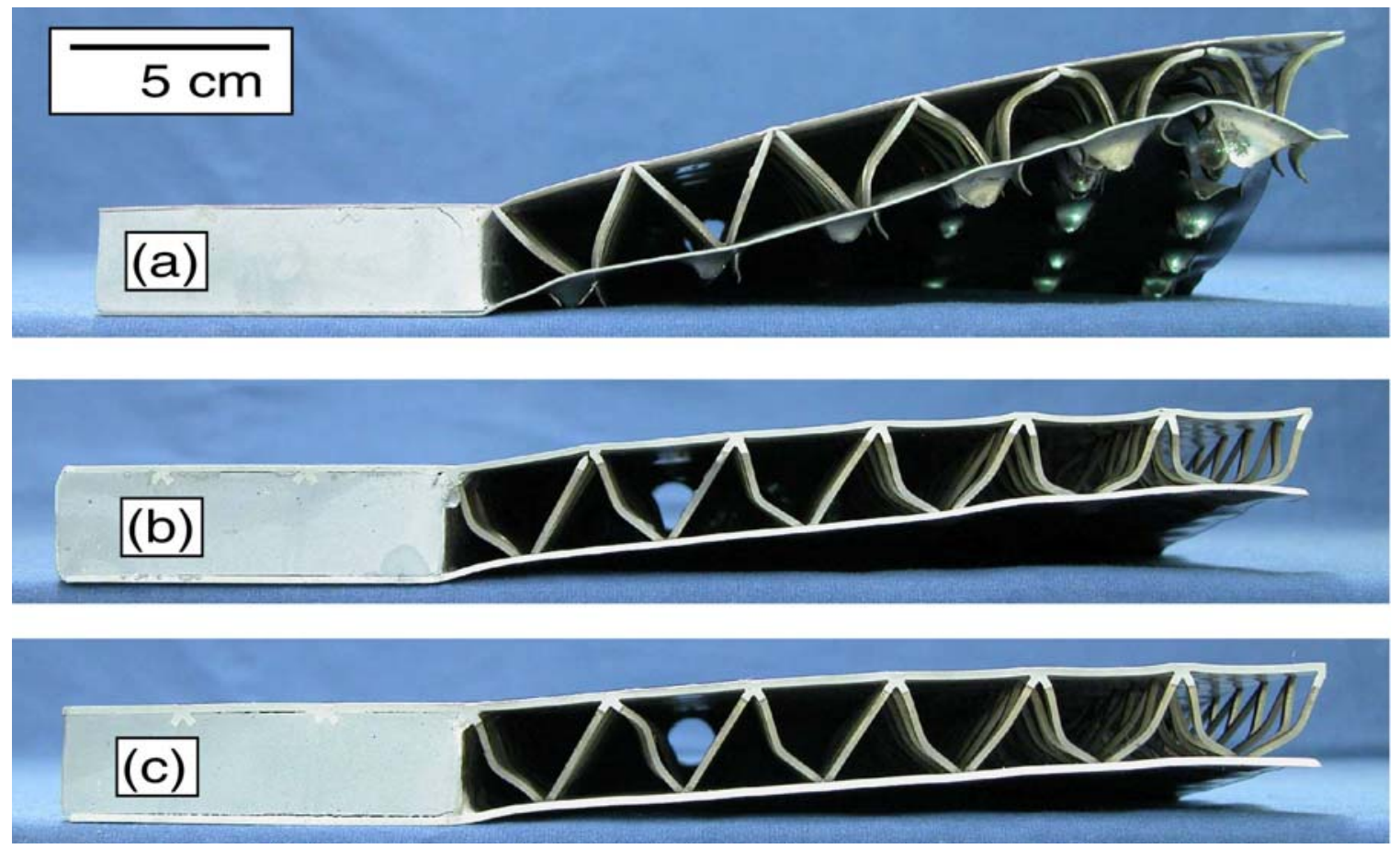

Figure 9. Effect of increasing face sheet thickness, $t_{f}$ upon the panel deformation for a constant impulse of $2.3 \mathrm{kPa}$.s (corresponding to a $150 \mathrm{~g} \mathrm{C}-4$ charge detonated at a standoff distance of $0.15 \mathrm{~m}$ ). Results are shown for face sheet thickness of (a) $t_{f}=0.76 \mathrm{~mm}$ (b) $t_{f}=$ $1.52 \mathrm{~mm}(\mathrm{c}) t_{f}=1.90 \mathrm{~mm}$. 

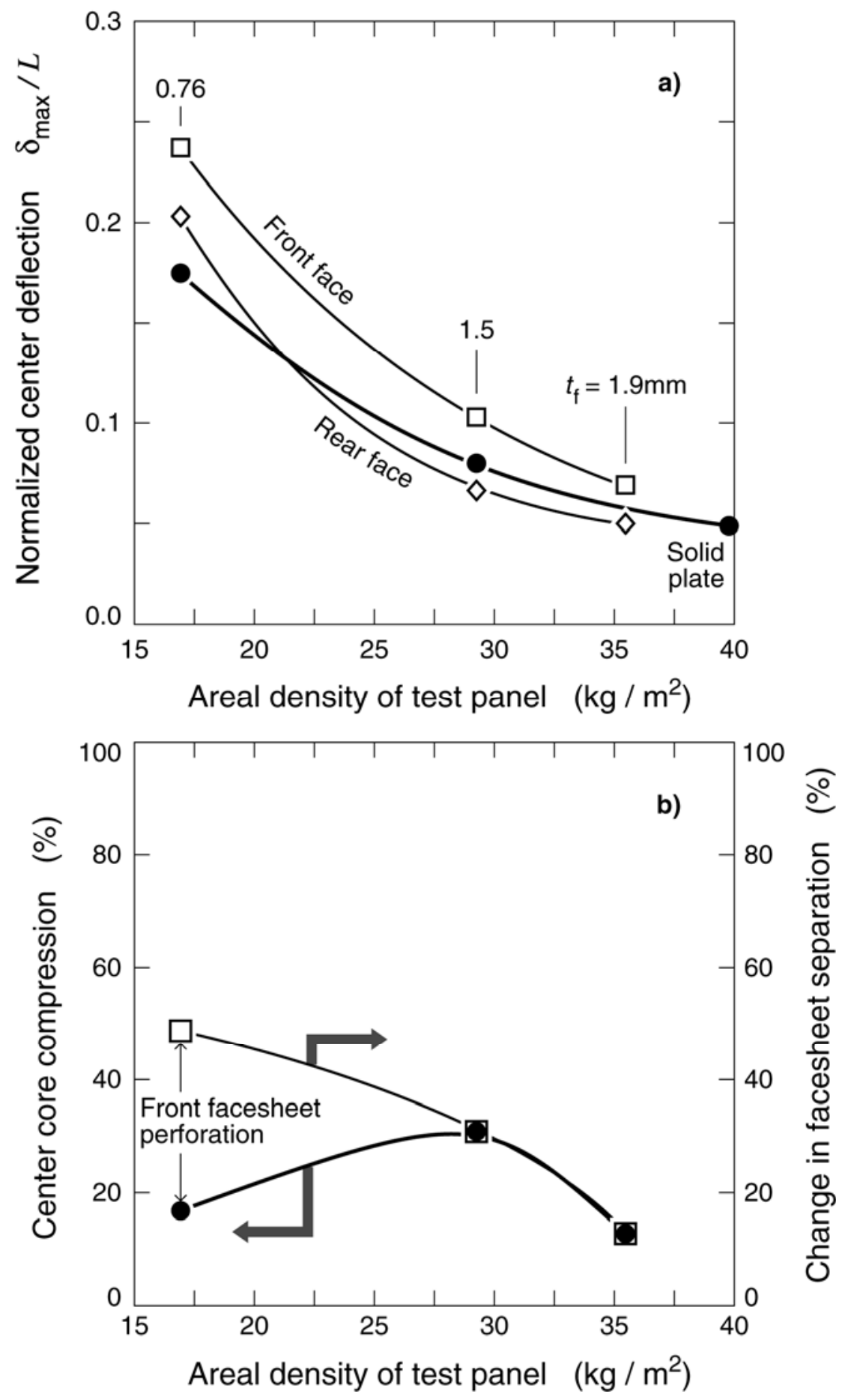

Figure 10. (a) Normalized center deflections of sandwich panel front and back faces and equivalent weight solid plate vs areal density of sandwich panel. (b) The core compression and change in sandwich panel facesheet separation variation with front face sheet areal density. The impulse was $2.3 \mathrm{kPa}$.s.

(a) 


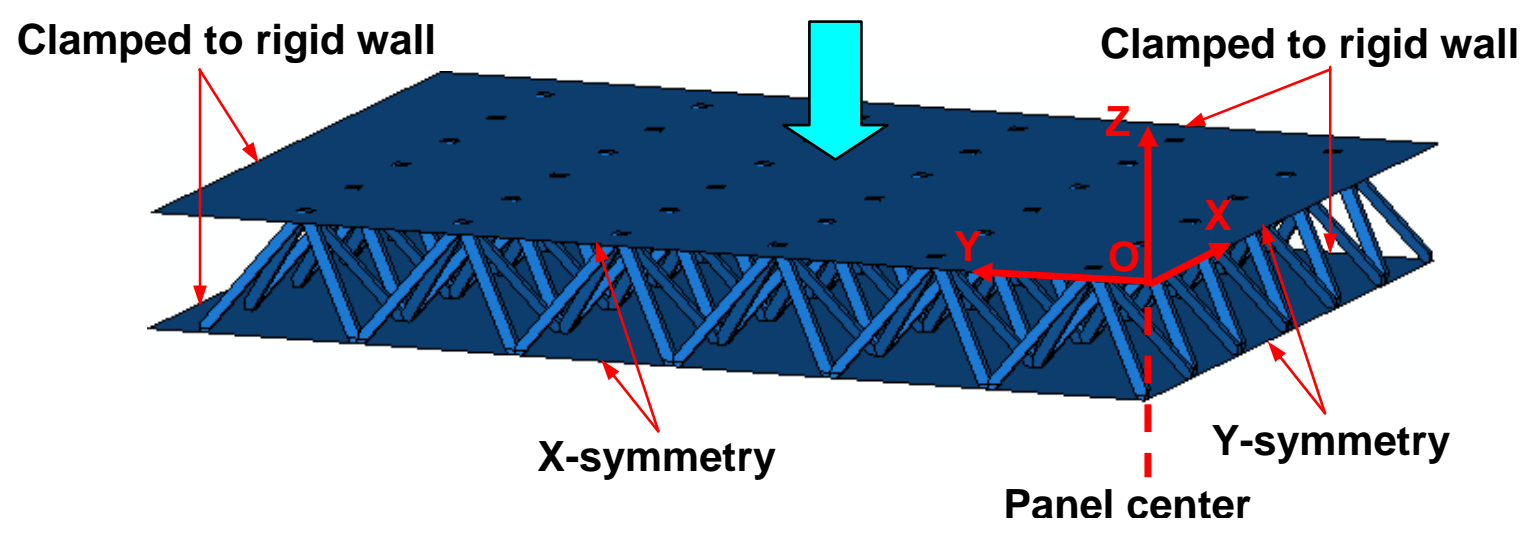

(b)

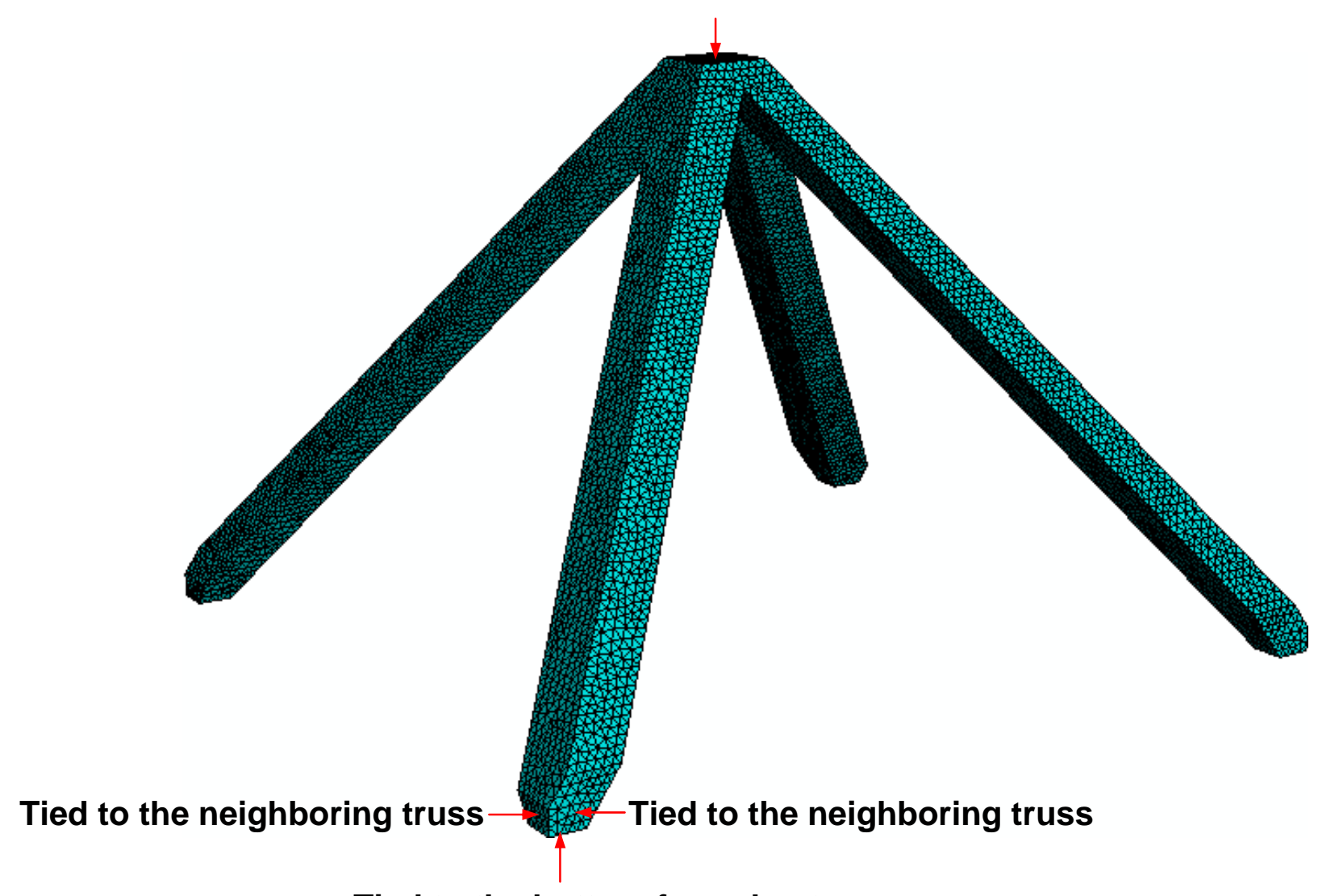

Tied to the bottom face sheet

Figure 11(a) Finite element model geometry and boundary conditions used to analyze the sandwich panel, and (b) one of the pyramidal truss unit cells showing meshed elements. 

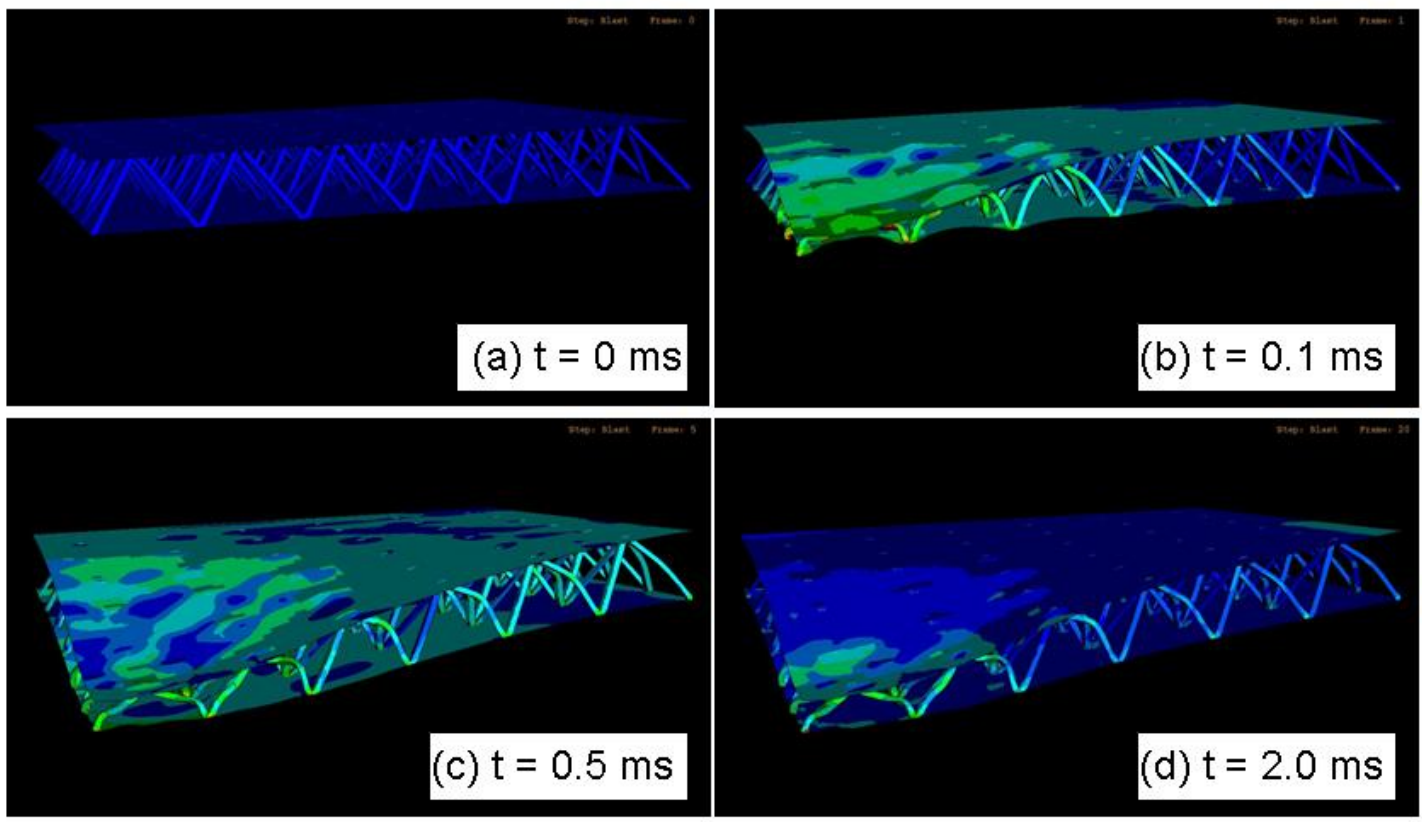

Figure 12. FEM predicted deformation time sequence for a quarter section of a sandwich panel with $1.52 \mathrm{~mm}$ thick face sheets and an imparted impulse of $7.6 \mathrm{kPa} . \mathrm{s}$ (corresponding to a $150 \mathrm{~g} \mathrm{C}-4$ charge detonated at a $7.5 \mathrm{~cm}$ standoff distance from the front sheet). (a) $\mathrm{t}=0 \mathrm{~ms}$ (b) $0.1 \mathrm{~ms}$ (c) $0.5 \mathrm{~ms}$ and (d) $2.0 \mathrm{~ms}$ after application of impulse. The green shades show areas of high plastic strain. 

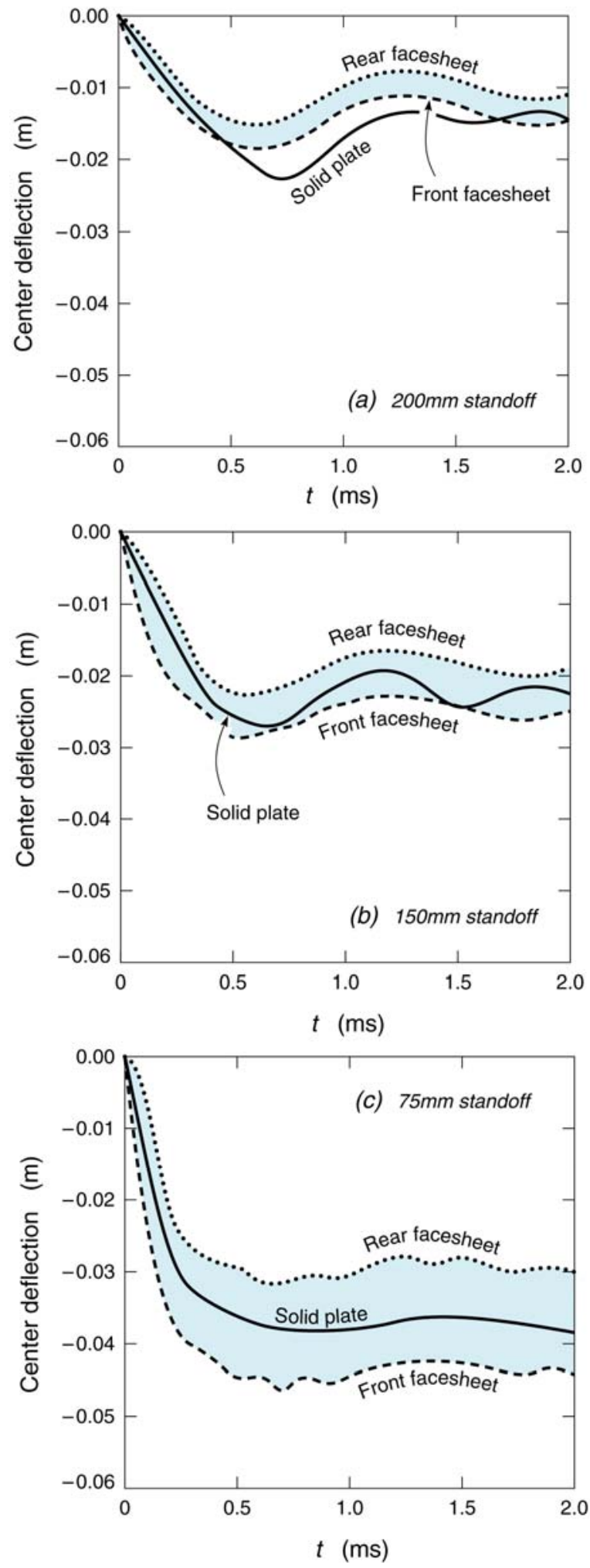

Figure 13. Predicted sandwich panel front and back face center displacements compared with the equivalent weight solid sheet for a face sheet thickness of $1.52 \mathrm{~mm}$. The curves correspond to stand off distances of (a) $0.20 \mathrm{~m}$, (b) $0.15 \mathrm{~m}$, and (c) $0.075 \mathrm{~m}$. 


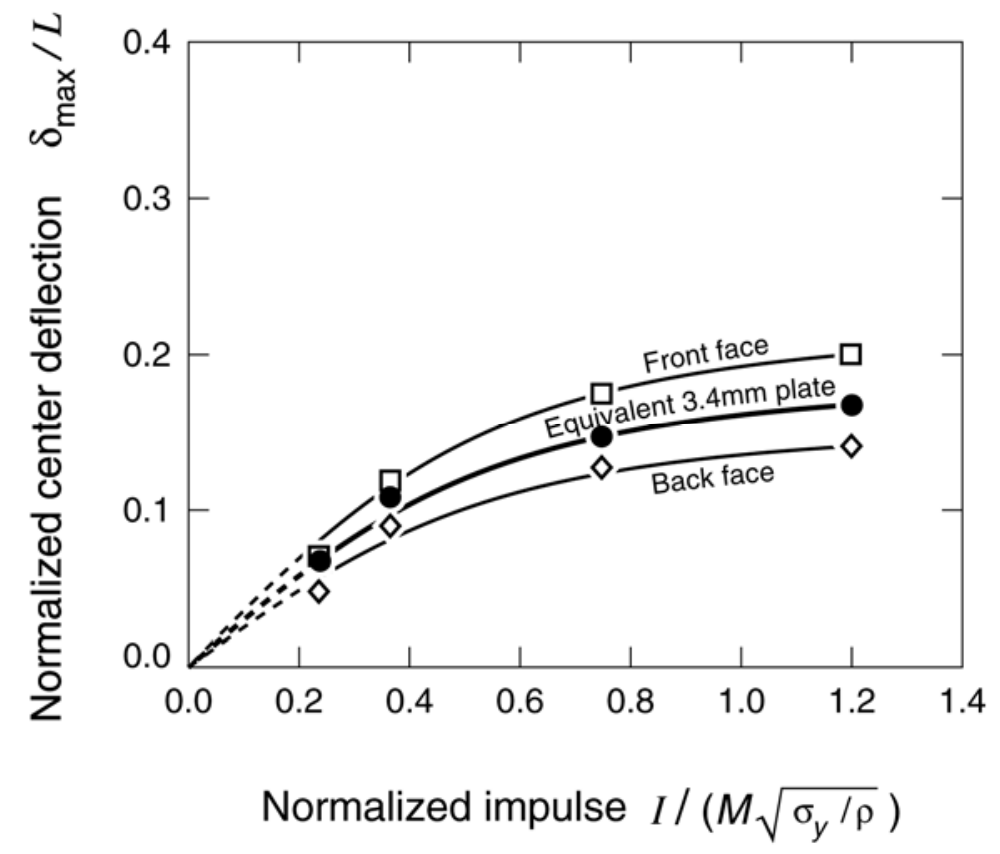

Figure 14. Predicted normalized center deflection of the sandwich panel front face, back face and equivalent weight solid sheet vs. the normalized impulse. 

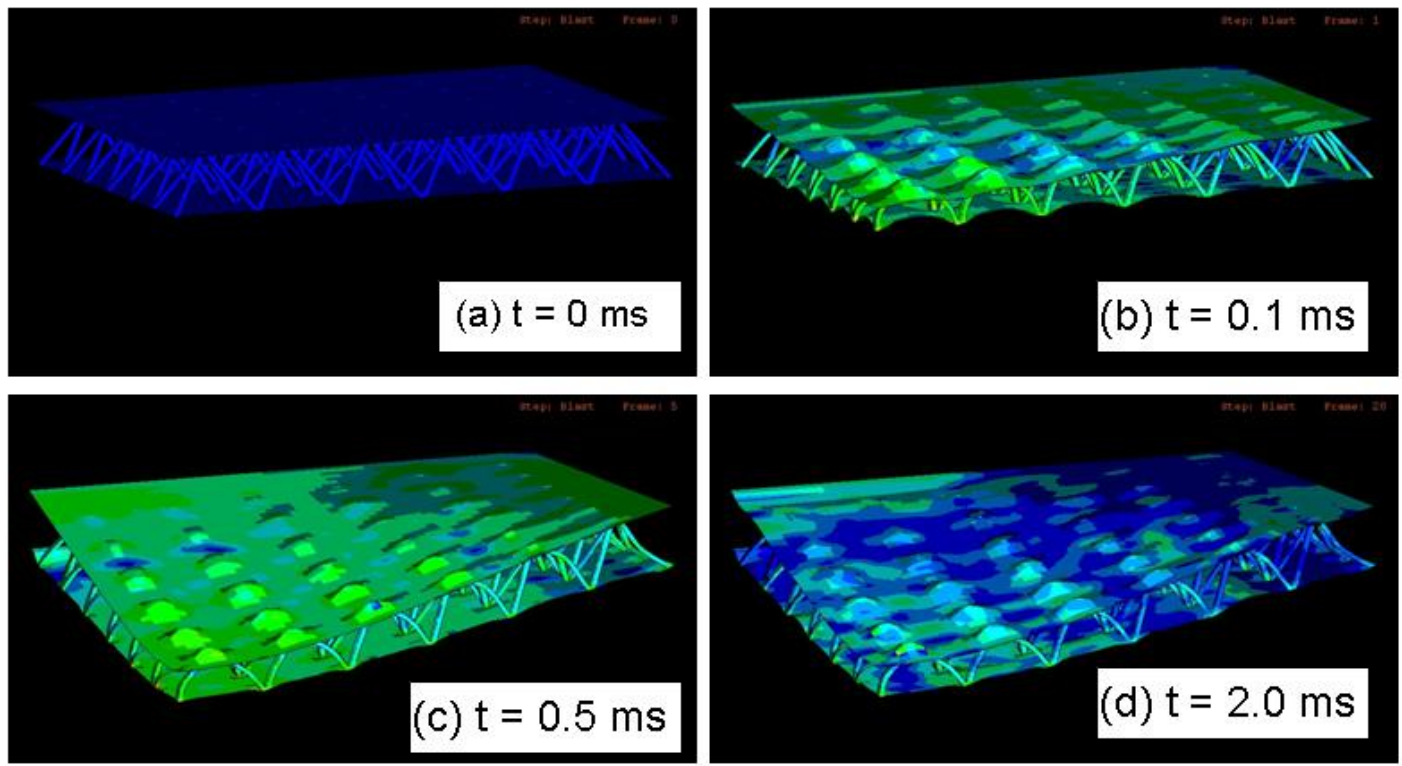

Figure 15. Predicted deformation time sequence for a quarter section of a sandwich panel with $0.76 \mathrm{~mm}$ thick face sheets and an impulse of $2.3 \mathrm{kPa} . \mathrm{s}$ (corresponding to a $150 \mathrm{~g} \mathrm{C}-4$ charge detonated at a $15 \mathrm{~cm}$ standoff distance from the front sheet). (a) $\mathrm{t}=0 \mathrm{~ms}$ (b) 0.1 ms (c) $0.5 \mathrm{~ms}$ (d) $2.0 \mathrm{~ms}$. The green shades show areas of high plastic strain. 

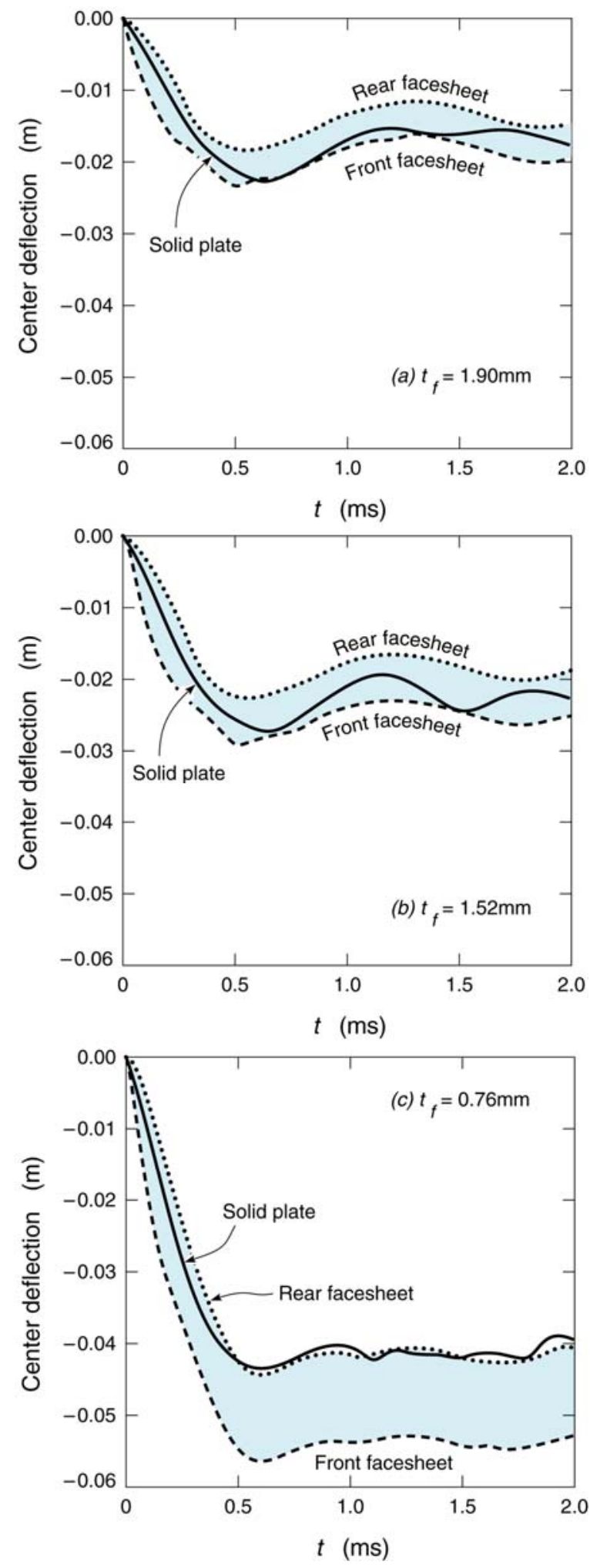

Figure 16. Predicted sandwich panel front and back face center displacements compared with the equivalent mass/unit area solid pane. The standoff distance was $0.15 \mathrm{~m}$ and impulse of $2.3 \mathrm{kPa} . s$. (a) $t_{f}=1.9 \mathrm{~mm}$, (b) $1.52 \mathrm{~mm}$, and (c) $0.76 \mathrm{~mm}$ face sheet thicknesses. 


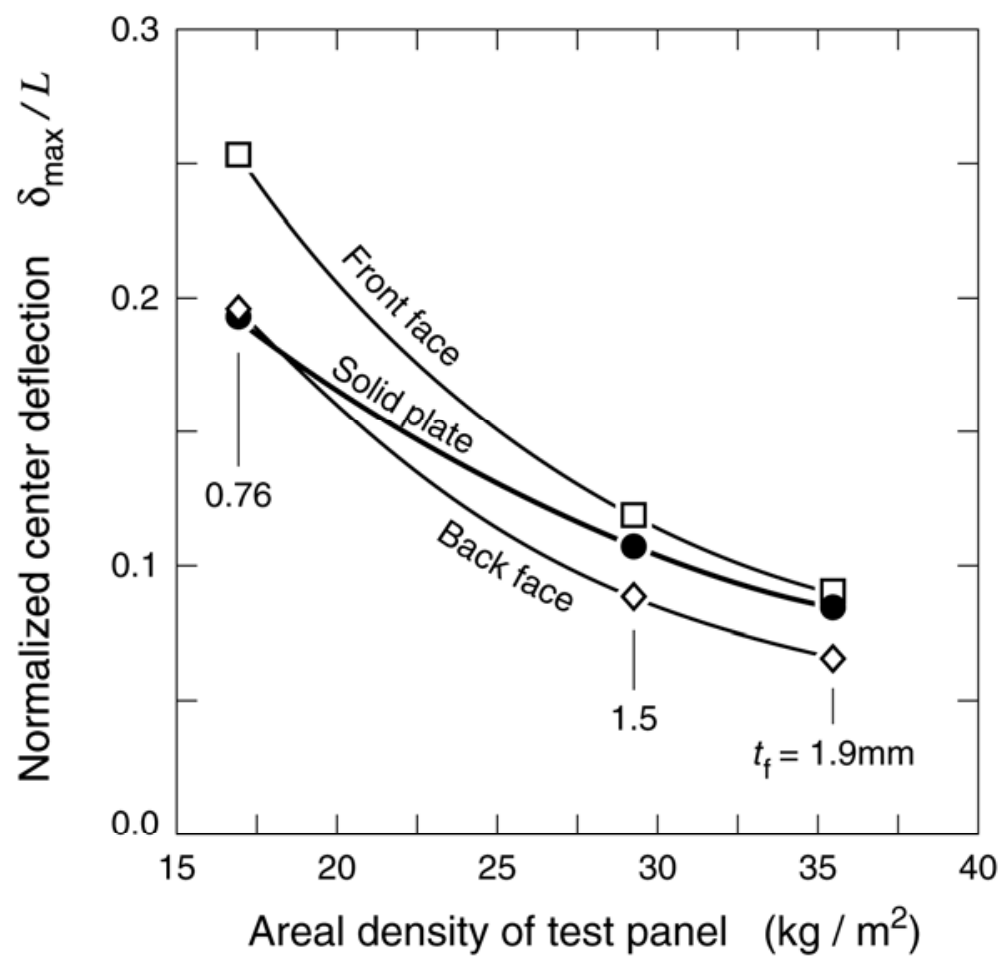

Figure 17. Predicted normalized center deflection of the sandwich panel front face, back face and equivalent weight solid sheet vs. panel areal density 
(a)
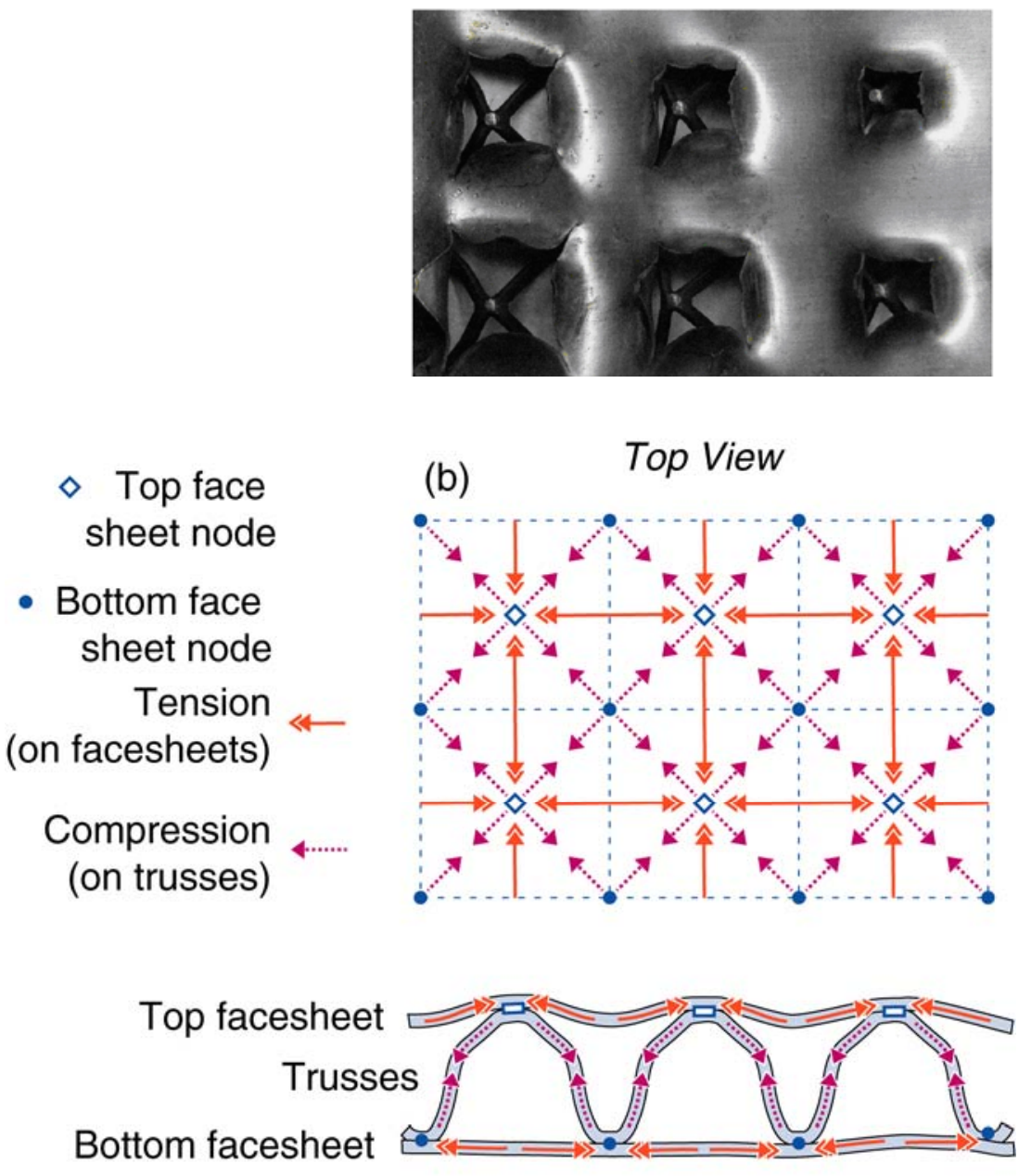

Side View

Figure 18. (a). Photograph showing tearing of front face sheet near the panel center. (b) Schematic top view of face sheet and truss core forces. (c) Schematic front view of face sheet and truss core forces. 
(a) Thick facesheet

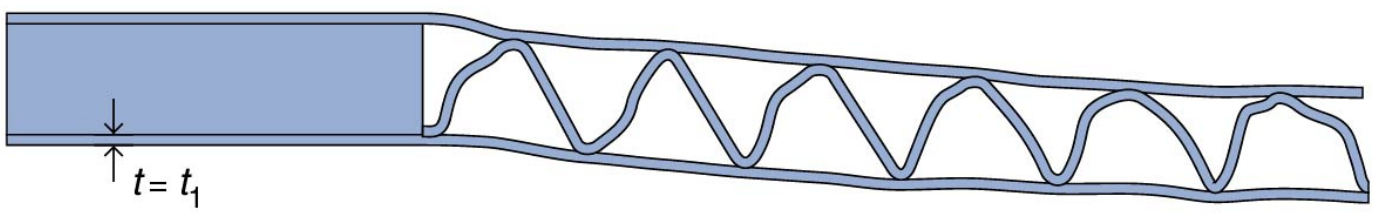

(b) Medium facesheet

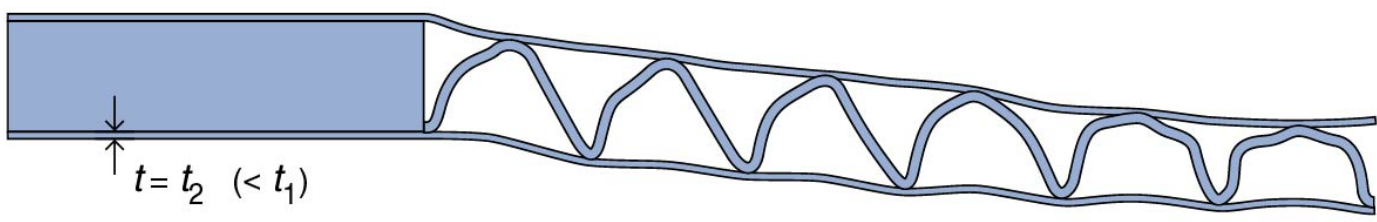

(c) Thin facesheet

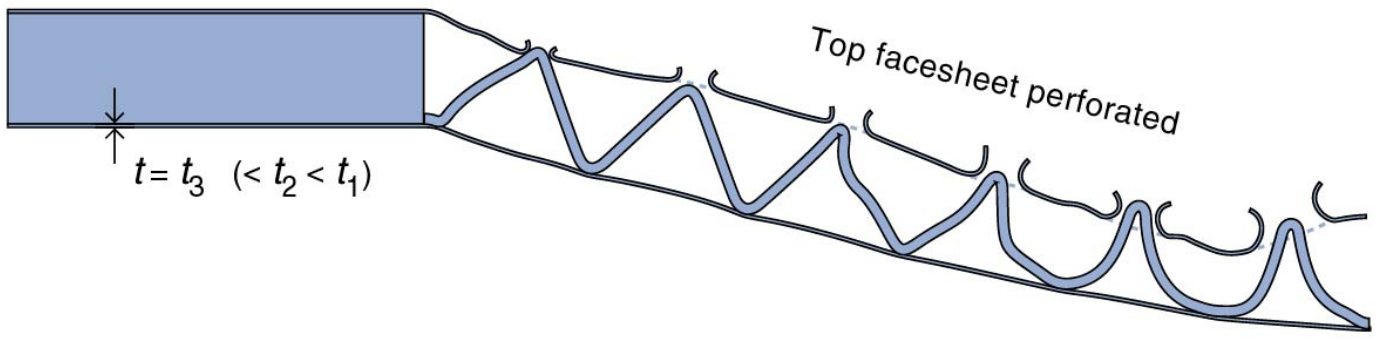

Figure 19. A schematic illustration showing the competing face sheet stretching and core crushing effects for three face sheet thicknesses. The initial velocity acquired by the face sheet during impulsive loading varies inversely with the face sheet mass/unit area. Thick faces acquire a relatively low initial velocity and are able to sustain the stretching forces without rupture. This forces core compression by truss buckling. Thin faces are rapidly and easily stretched. They suffer rupture before the (inertially strengthened) core members significantly buckle. 


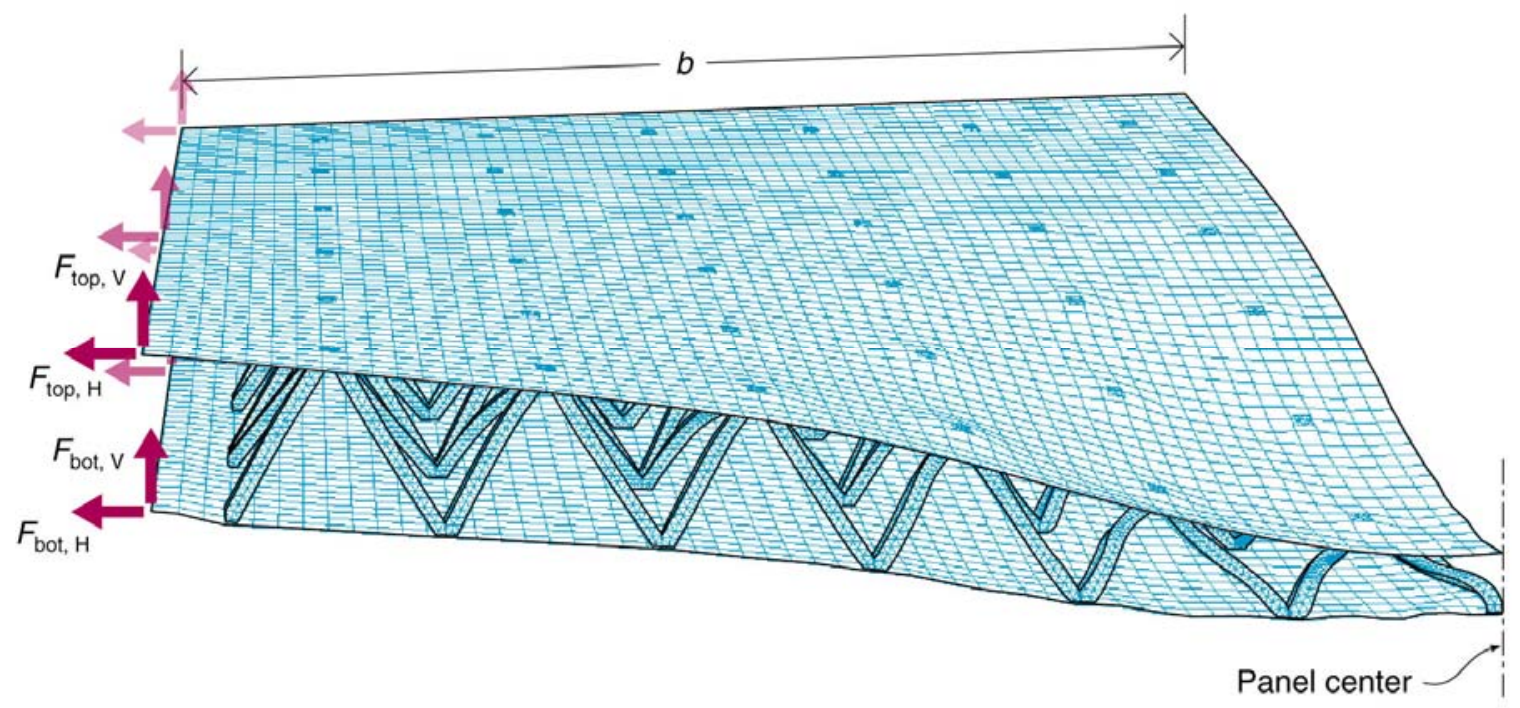

Figure 20. Definition of the horizontal and vertical reaction forces transmitted to the edge supports. 
Vertical Force at Support
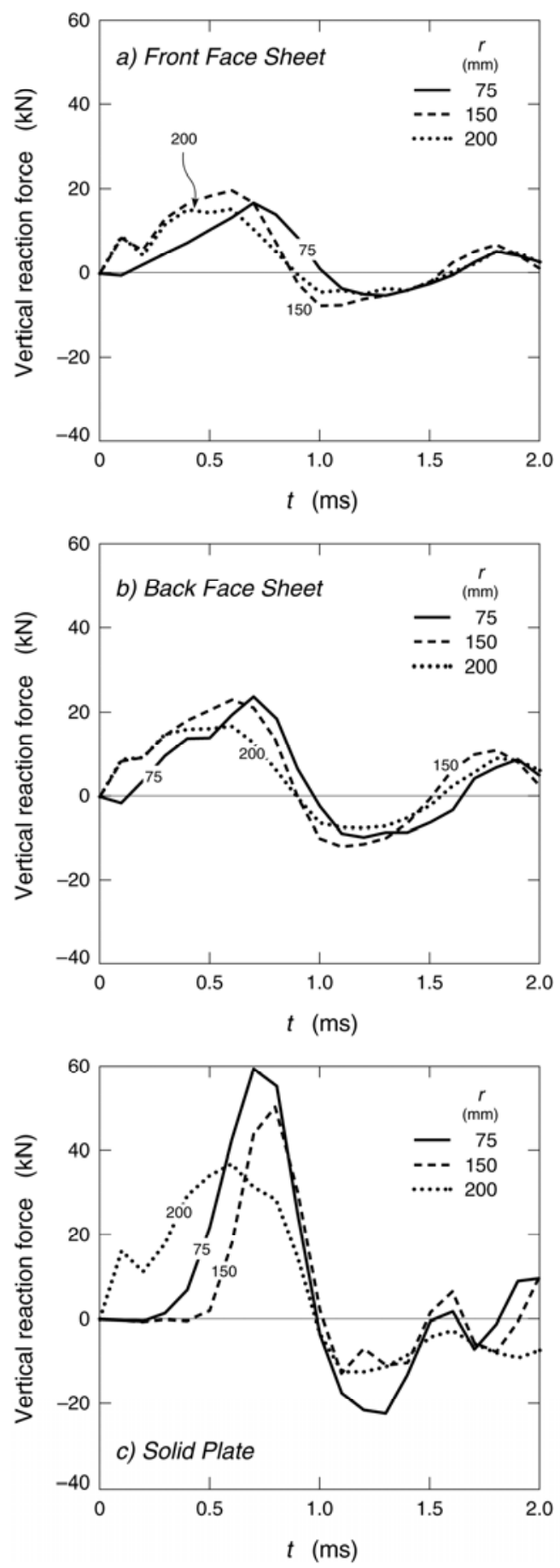

Horizontal Force at Support
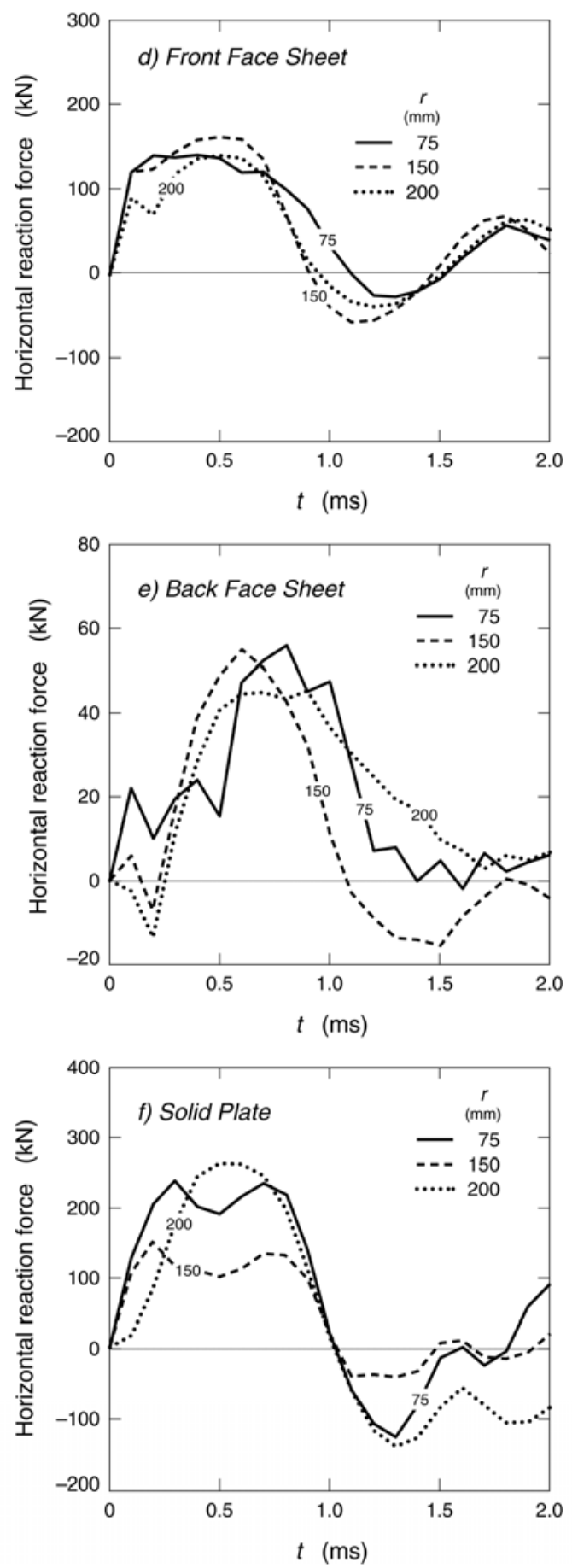

Figure 21. (a, b and c) vertical and (d, e and f) horizontal reaction force transmitted to supports as a function of time for three stand off distances. 

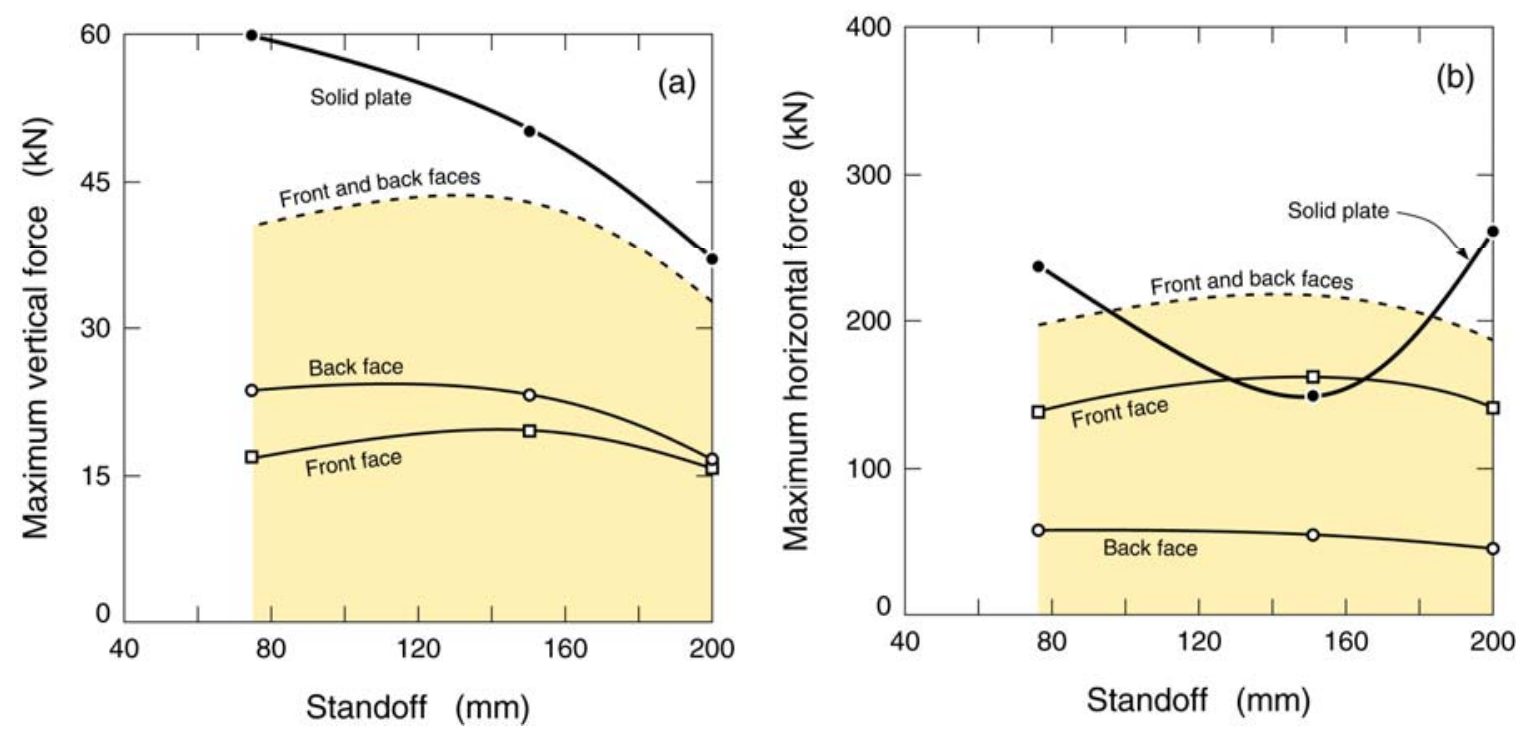

Figure 22. The peak forces transmitted to supports. (a) Vertical and (b) horizontal force component variations with standoff distance. 


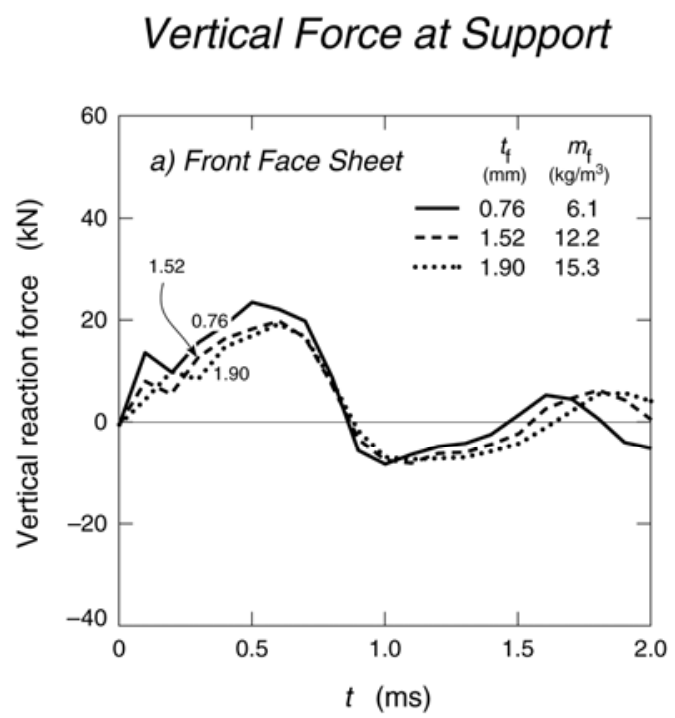

Horizontal Force at Support
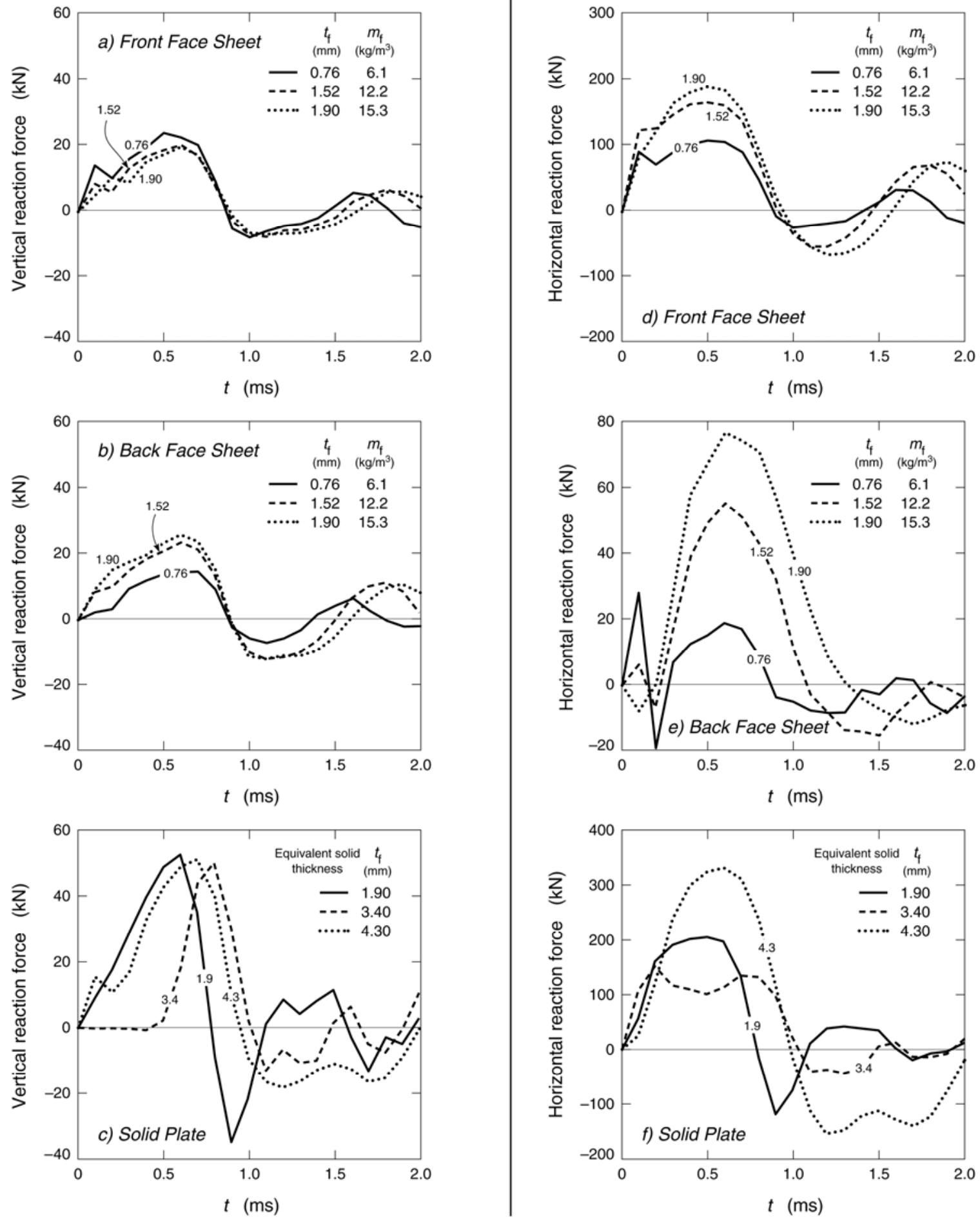

Figure 23. (a, b and c) vertical and (d, e and f) horizontal reaction force transmitted to supports as a function of time for three face sheet thicknesses. 

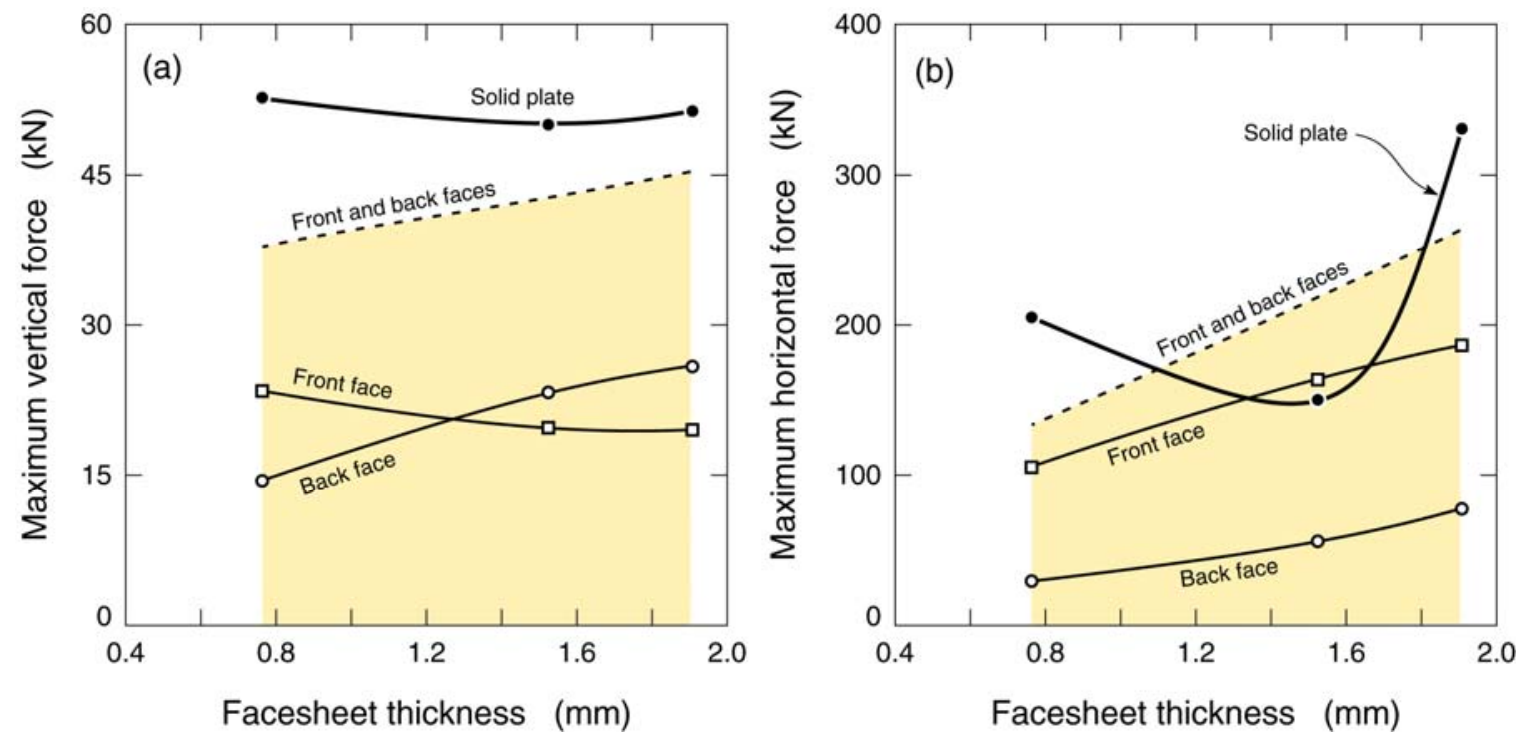

Figure 24. The variation of the peak forces transmitted to supports as a function of face sheet thickness. (a) Vertical and (b) horizontal force component variation. 